\title{
Parameter uncertainty and elasticity analyses of a population model: setting research priorities for shearwaters
}

\author{
C.M. Hunter ${ }^{\mathrm{a}, *}$, H. Moller ${ }^{\mathrm{a}}$, D. Fletcher ${ }^{\mathrm{b}}$ \\ a Department of Zoology, University of Otago, P.O. Box 56, Dunedin, New Zealand \\ ${ }^{\mathrm{b}}$ Department of Mathematics and Statistics, University of Otago, P.O. Box 56, Dunedin, New Zealand
}

Received 10 November 1999; received in revised form 9 May 2000; accepted 6 June 2000

\begin{abstract}
The difference between parameter uncertainty and elasticity analyses of a deterministic matrix model was evaluated using the Short-tailed Shearwater (Puffinus tenuirostris) as a case study. A total of 5000 simulations of the model were run with input parameters randomly selected from uniform distributions between the upper and lower $95 \%$ confidence limits for each parameter. A multiple regression equation was used to relate population growth to all input parameters, two-way interactions and quadratics. Elasticity and parameter uncertainty coefficients were estimated as the percent change in population growth rate when the minimum and maximum value of each parameter were substituted into the regression equation, with all other parameters set at their mean values. Minimum and maximum values were set at the $95 \%$ confidence limits for the parameter uncertainty analysis, and at $\pm 5 \%$ of both mean survival and mean mortality estimates for the elasticity analyses. Parameter rankings differed among the uncertainty and two elasticity analyses. Probability of pre-breeders staying in the colony and probability of first breeding ranked highly in the parameter uncertainty analysis. Survival rates had higher elasticity coefficient rankings when $\pm 5 \%$ of mean survival was used because altering proportions close to one results in a wider parameter range. The importance of interactions was explored but their importance in this example was found to be low. Incorporating breeding age specific data more closely approximated observed population demographic structure but had little effect on the magnitude or rankings of the elasticity or parameter uncertainty coefficients. The utility of parameter uncertainty and elasticity analyses differ. The former determines how uncertainty in parameter estimation influences model outcomes and is therefore valuable for setting research priorities. The latter determines the effect on model outcomes of altering parameter input levels, so is more valuable for ranking the potential effectiveness of alternative management strategies. (C) 2000 Elsevier Science B.V. All rights reserved.
\end{abstract}

Keywords: Demography; Simulation model; Uncertainty analysis; Elasticity analysis; Shearwaters

\section{Introduction}

* Corresponding author. Tel.: + 64-3-4797665; fax: + 64-34797584.

E-mail address: christine.hunter@stonebow.otago.ac.nz (C.M. Hunter).

Demographic perturbation analysis evaluates how sensitive model output (for example, population size, growth rate or risk of extinction) is to 
changes in input parameter values (Beck, 1983; de Kroon et al., 1986; Swartzman and Kaluzny, 1987; van Groenendael et al., 1988; Burgman et al., 1993; Hamby, 1994; Caswell, 2000; de Kroon et al., 2000). This commonly involves changing parameter values, either singly or in various combinations, by an absolute amount or a set percentage and observing the changes in model output. Perturbation analysis may be used to determine which parameters: (i) cause the greatest change in model output when altered; (ii) contribute most to the variability in model output through uncertainty in their estimation; or (iii) are insignificant and can be eliminated from the model (Goodman, 1980; Swartzman and Kaluzny, 1987; Possingham et al., 1993; Hamby, 1994; McCarthy et al., 1996; Starfield, 1997).

Model output may respond to parameters in two ways: either model results may be highly correlated with an input parameter so that small changes in the input value result in significant changes in model output, or the variability, or uncertainty, associated with an input parameter can be propagated through the model resulting in a large contribution to the output variability (Hamby, 1994). This paper distinguishes between elasticity analysis, in which sensitive parameters are defined as those that have a large proportional influence on population growth rate, and parameter uncertainty analysis, in which the importance of parameters is defined as those for which uncertainty in estimation contributes substantially to the uncertainty in population growth rate (Hamby, 1994; Janssen, 1994; Kleijnen, 1994).

A large number of techniques have been utilized for conducting perturbation analyses (Hamby, 1994; Caswell, 2000). The most fundamental analytical techniques involve calculation of sensitivity or elasticity coefficients using first derivatives. For deterministic models sensitivity coefficients are defined as the first derivative of model output with respect to the parameters (Tomovic, 1963; Caswell, 1978, 1989). Elasticity coefficients (proportional sensitivities) are the relative change in population growth rate resulting from a relative change in the input parameters (de Kroon et al., 1986; Caswell, 1989). Sensitivity and elasticity coefficients of simulation models are usually measured by varying each parameter in turn by a specified amount or percentage around its estimated value and measuring the resulting change in the model output (Beck, 1983; Swartzman and Kaluzny, 1987; Burgman et al., 1993; McCarthy et al., 1995; Dixon et al., 1997). For deterministic models these two approaches, although representing different methodologies (analytical and empirical), should give essentially the same results.

In contrast to sensitivities and elasticities, which assess how much model output is affected by variations in the mean level of parameter inputs, parameter uncertainties measure how much the variability in parameter estimates contributes to the uncertainty in model outcomes. If improvement in model predictions is an objective, it is obviously more advantageous to minimize variability in parameter estimates that produce large variations in model outcomes than those that produce only small variations. The influence of uncertainty in parameter estimation can be measured by the response of model output to changes in parameter levels proportional to the parameter standard deviation, rather than the mean (Swartzman, 1979; McCarthy et al., 1996; Ehrlen and van Groenendael, 1998de Kroon et al., 2000; Slooten et al., in press).

Modelling is particularly valuable for exploring the demographic behaviour of long-lived species such as shearwaters that present many logistical challenges to monitoring even basic demographic rates. However, few models have been developed for Procellariformes. The authors are in the early stages of a long-term monitoring program for Sooty Shearwaters (Puffinus griseus) to assess population trends and impacts of harvest (Moller, 1996; Taiepa et al., 1997). Using detailed data available from a long-term study of Short-tailed Shearwaters (Puffinus tenuirostris), a closely related species, this paper seeks to evaluate where research efforts can be most effectively focused.

The Short-tailed Shearwater is a medium-sized, burrow-nesting procellariiform seabird. They breed annually in southeastern Australia, mainly on islands around Tasmania, and migrate to northern Pacific waters for the Australian winter. Short-tailed Shearwaters are the most abundant 
seabird in Australia, with individual colonies ranging in size from a few hundred to several million pairs (Serventy, 1967; Serventy and Curry, 1984; Marchant and Higgins, 1990; Wooller and Bradley, 1999).

This paper highlights the differences between elasticity and parameter uncertainity analyses using the Short-tailed Shearwater as a case study. Parameter elasticity and uncertainty coefficients are evaluated for a deterministic matrix projection model with the goal of providing advice on future research priorities to monitor population trends and to identify safe annual harvest limits. The specific objectives were to: (i) assess how well two alternative models, that differed in parameterization of the breeding population, matched observed population demographics; (ii) determine the elasticity of population growth rate to input parameters; (iii) determine the influence of uncertainty in parameter estimation on population growth rate; (iv) determine the influence of twoway interactions between parameters on population growth rate; (v) compare the rankings of input parameters in the parameter elasticity and uncertainty analyses; and (vi) determine whether the models can be useful in predicting possible sustainable harvest levels.

\section{Methods}

\subsection{Model structure}

Population growth rate was modelled using a deterministic matrix model (Leslie, 1945; Burgman et al., 1993) programmed in an Excel $^{\circledR}$ spreadsheet. Only females are included in the model, it was assumed sufficient males exist to pair with all available females. The model is stagestructured (Caswell, 1989), with pre-breeders classified by age $(1-15)$ and post-breeding females classified by 'breeding age' (0-25), which represents the number of years since the first breeding attempt irrespective of the actual age of first breeding (Fig. 1). In each year following the initial breeding attempt, fecund females were divided into breeders and non-breeders based on whether they bred or skipped breeding in the current year.
This allows distinction between pre-breeders (nonfecund) and non-breeders (fecund, but not breeding in the current year) throughout the paper. Short-tailed Shearwaters lay a single egg (Serventy, 1967; Serventy and Curry, 1984), so the number of eggs laid at the start of a given year was considered to be equal to the number of breeding females. The number of eggs that survive to fledging is determined by breeding success, and a juvenile re-appearance rate determines survival from fledging to 1 year. Immigrants enter the model at pre-breeder age 3. Pre-breeders were allowed to begin breeding between the ages of 2 and 15 and were subject to emigration from age 3 . A parameter 'probability of first breeding' (PFB) controlled the rate of flow of females from each pre-breeder age cohort into the breeding segment of the population. In preference to truncating the model at an arbitrary age, breeders and nonbreeders that reached breeding age class 25 and survived another year were re-cycled back into the 25 year breeding and non-breeding age classes (Caswell 1989).

\subsection{Parameter estimation}

The model contains 12 input parameters (Table 1) which were estimated from a long-term study of Short-tailed Shearwaters on Fisher Island, in Bass Strait, Tasmania. A small colony of 100-200 breeding adults has been studied there since 1947 (Serventy, 1967; Bradley and Wooller, 1989; Wooller et al., 1990; Wooller and Bradley, 1999; Bradley et al., 1991). All breeding individuals in the colony have been identified since 1950 and their mates and reproductive performance recorded each year. Methods for the Fisher Island study are discussed in Serventy (1967) and Serventy and Curry (1984).

Two versions of the model were run. In the first, hereafter referred to as the Average Breeder Model (ABM), a single mean value was used for breeder survival, probability of breeders skipping, probability of non-breeders skipping and breeding success for all breeding ages. The second version, hereafter referred to as the Breeding Age Model (BAM), allowed these four parameters to vary depending on age since first breeding. In the BAM 
a polynomial was used to predict the parameter values for each breeding age as depicted in Fig. $2 \mathrm{a}-\mathrm{c}$. Weighted regressions were used to fit the polynomials because sample sizes were much lower for the higher age groups. Breeding success was weighted by the number of breeding adults in each breeding age (Table 24.2, Wooller et al., 1989) and mortality and proportion of birds skipping breeding were weighted by the number of breeding birds present at the colony plus the number of birds skipping breeding for each breeding age (Table 24.1, Wooller et al., 1990).

An estimate of the mean, upper $95 \%$ confidence limit and lower 95\% confidence limit were calculated for each input parameter (Table 1). Parameter estimates were based on small sample sizes for older birds, so data for males and females were pooled whenever possible. Survival, age at first breeding and rates of skipping breeding have been shown to vary little between the sexes for Shorttailed Shearwaters (Bradley et al., 1989; Wooller et al., 1990). Statistically significant differences between sexes have only been found in the percentage of breeding birds present at the colony but not associated with an egg (males 18\%, females $15 \%$ ). However, this is a minor difference and may result from different attendance behaviours rather than reflecting a real difference in demographic rates between the sexes, allowing confidence that pooling data for both sexes to increase the statistical precision of parameter estimates is reasonable.

To vary breeding-age-specific rates for breeder survival, probability of breeders skipping, proba-

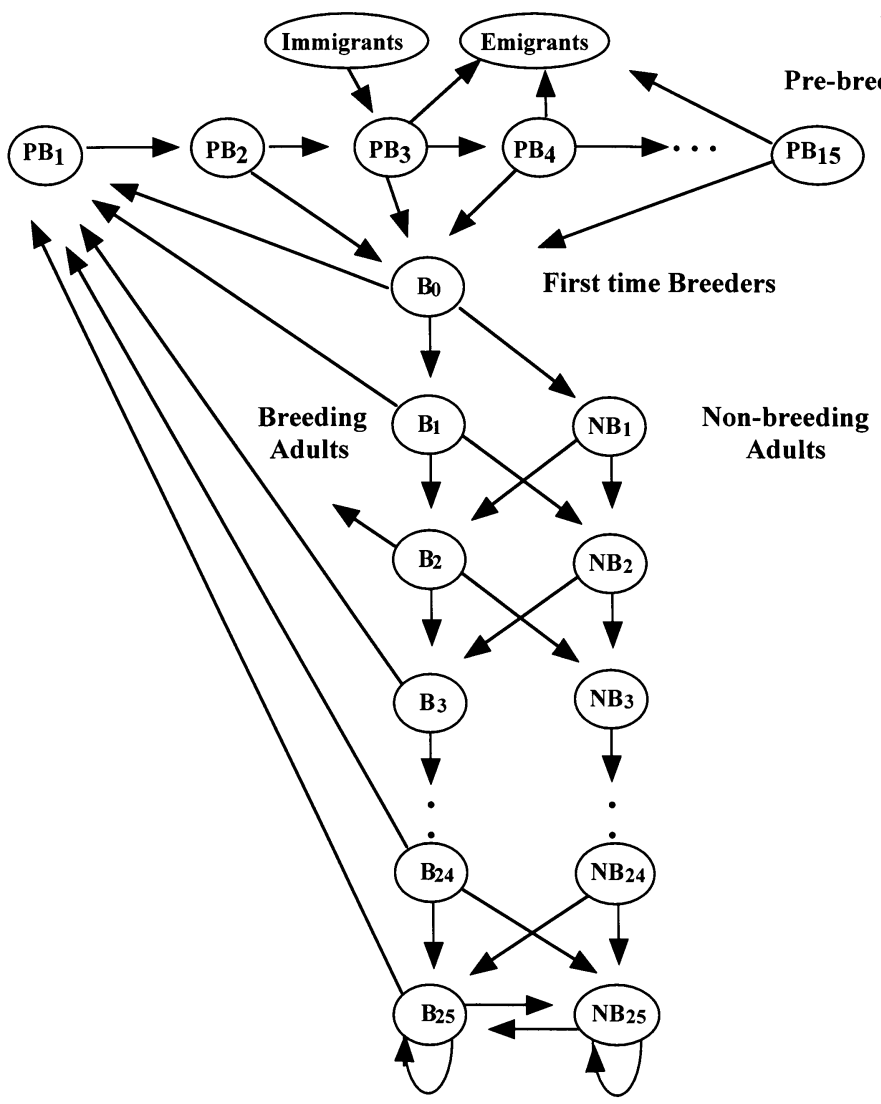

Fig. 1. Flow diagram of model structure. $\mathrm{PB}_{x}$, pre-breeder of age $x ; \mathrm{B}_{x}$, breeder of breeding age $x$; and $\mathrm{NB}_{x}$, non-breeder of breeding age $x$. 
Table 1

Estimates of the mean and upper and lower $95 \%$ confidence limits for input parameters ${ }^{\mathrm{a}}$

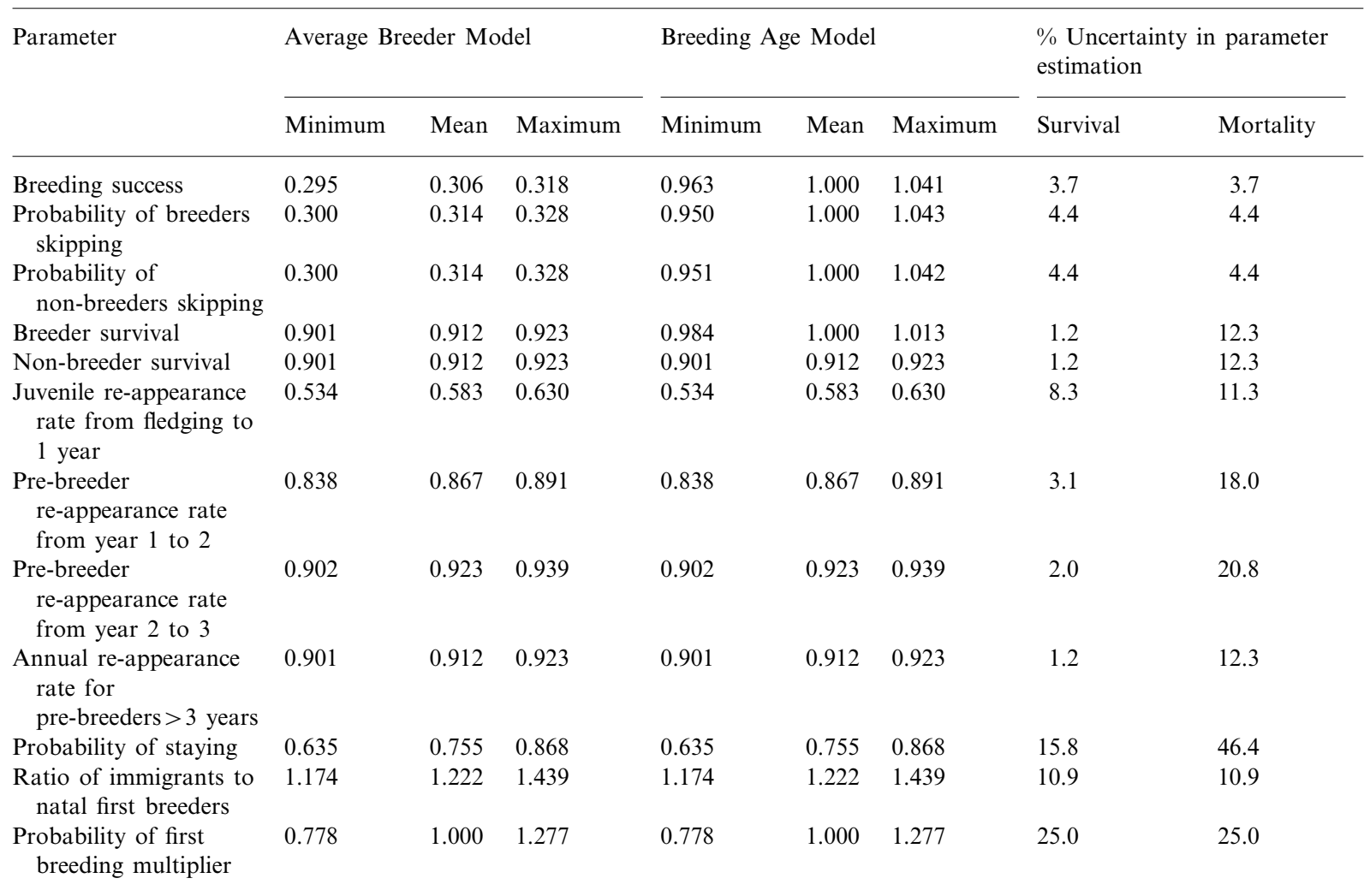

${ }^{a}$ Breeding Age Model estimates for breeding success, skipping rates and breeder survival are multipliers. Percent uncertainty in parameter estimation is the average difference between the mean and the upper or lower limit expressed as a percentage of the mean.

bility of non-breeders skipping and breeding success in the BAM the values predicted by the polynomial equations for each breeding age were multiplied by a constant $k$. For $k=1$, this gives the estimated mean rate for each breeding age shown by the solid lines in Fig. $2 \mathrm{a}-\mathrm{c}$. For $k>1$, the predicted rate for each breeding age was increased by the same proportion above its mean and for $k<1$, the predicted rate for each breeding age was decreased by the same proportion below its mean. The upper and lower 95\% confidence limits for the multipliers were calculated so that the percentage change in the weighted mean estimate for each rate (over all breeding ages) predicted by the polynomial was equivalent to the percentage change in the $95 \%$ confidence interval (CI) for the corresponding parameter in the ABM.

\subsubsection{Breeding success}

Breeding success (BS) was defined as the proportion of eggs that survived from egg-laying to fledging. The estimate of the mean and 95\% CI limits for breeding success $(0.61 \pm 0.02$, figures in parentheses are $\pm 95 \%$ CI unless otherwise stated) used in the ABM were determined from Wooller et al. (1990). The polynomial used to predict breeding age specific rates of breeding success (Fig. 2a) in the BAM was determined from Wooller et al. (1990). These figures were halved to represent female chicks only (Table 1).

\subsubsection{Skipping rates}

A skipping breeding rate was defined as the proportion of birds known to have bred the year before that did not attempt to breed in the current 
year. A skipping breeding rate of $0.314( \pm 0.014$; Wooller et al., 1990) was assigned for breeders (BRK) of all breeding ages in the ABM. The polynomial used to predict skipping rates of breeders in the BAM (Fig. 2b) was determined from Wooller et al. (1990). Skipping rates of
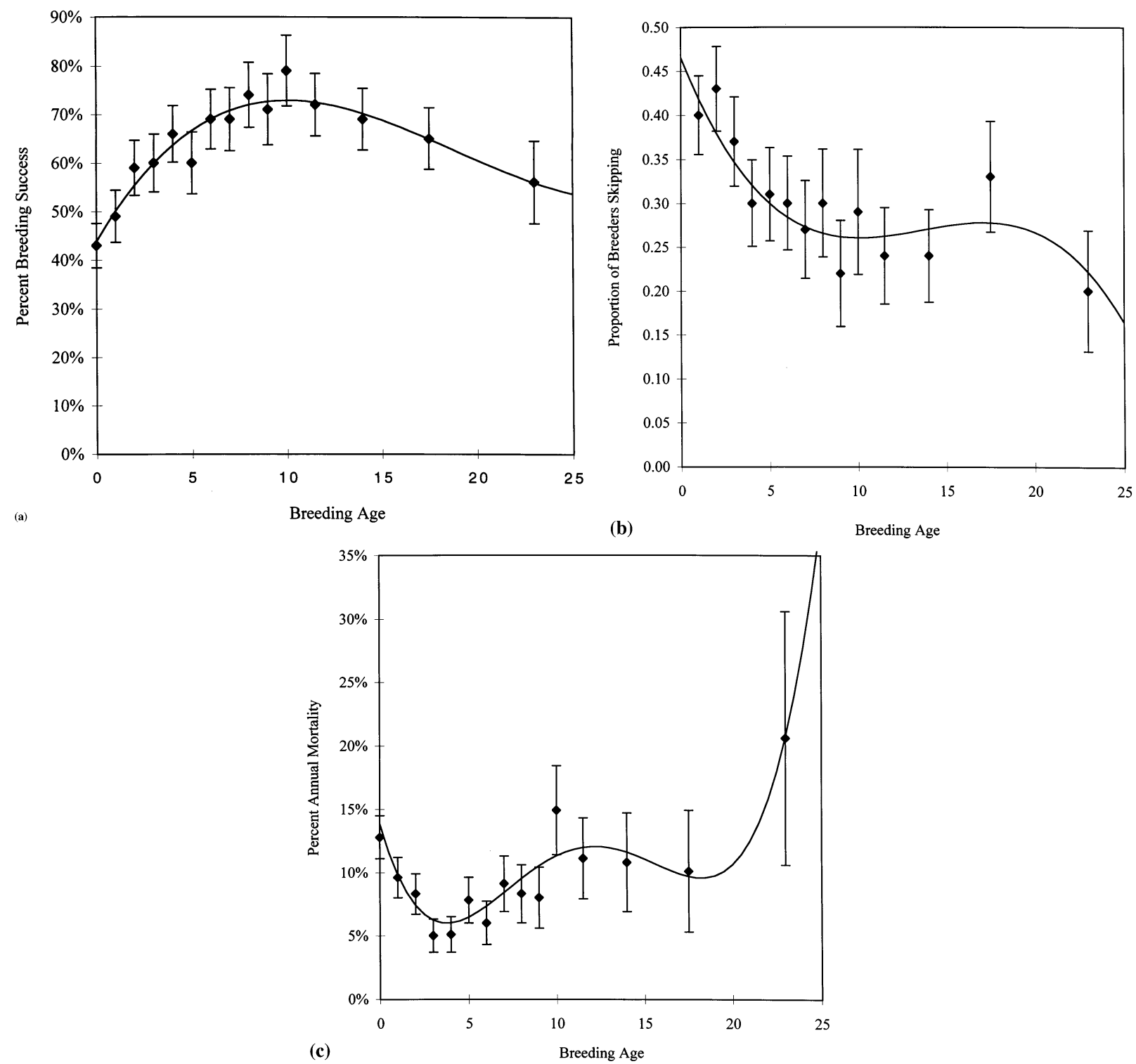

Fig. 2. (a) Percent breeding success vs. breeding age for Short-tailed Shearwaters on Fisher Island. Solid line represents the equation $\left(y=-0.00003 x^{4}+0.0095 x^{3}-0.4705 x^{2}+6.695 x+43.799\right)$ used to estimate breeding success for each breeding age. Error bars are binomial confidence limits. Data are from Wooller et al. (1990). (b) Proportion of breeders skipping breeding vs. breeding age for Short-tailed Shearwaters on Fisher Island. Solid line represents the equation $\left(y=-0.0098 x^{3}+0.4004 x^{2}-5.072 x+46.548\right)$ used to estimate the skipping rate for each breeding age. Error bars are binomial confidence limits. Data are from Wooller et al. (1990). (c) Percent annual mortality vs. breeding age for Short-tailed Shearwaters on Fisher Island. Error bars are \pm 1 S.E. Solid line represents the equation $\left(y=0.0015 x^{4}-0.0678 x^{3}+1.0012 x^{2}-4.978 x+13.865\right)$ used to estimate mortality for each breeding age. Data are from Wooller et al. (1990). 
Table 2

Calculation of the mean, minimum and maximum annual probability of re-appearance from fledging to age 4 for Short-tailed Shearwaters on Fisher Island

\begin{tabular}{|c|c|c|c|}
\hline & \multicolumn{3}{|l|}{ Scenario } \\
\hline & Minimum & Mean & Maximum \\
\hline Mean age of first arrival & Lower $95 \%$ CI 4.023 years & Mean 4.158 years & Upper $95 \%$ CI 4.293 years \\
\hline 0-4 year re-appearance rate & Lower $95 \%$ CI 0.371 & Mean 0.437 & Upper $95 \%$ CI 0.501 \\
\hline & $\mathrm{PBR}_{2}=0.902$ & $\mathrm{PBR}_{2}=0.923$ & $\mathrm{PBR}_{2}=0.939$ \\
\hline & $\mathrm{PBR}_{3}=0.919$ & $\mathrm{PBR}_{3}=0.938$ & $\mathrm{PBR}_{3}=0.951$ \\
\hline
\end{tabular}

non-breeders (NBRK) were assumed to be equal to skipping rates of breeders (Table 1).

\subsubsection{Survival rates}

A mean probability of annual survival of 0.912 $( \pm 0.011)$ was assigned to breeders (BRS) in the ABM (Wooller et al., 1990). Breeder survival rates predicted by the polynomial used in the BAM (Fig. 2c) were estimated from Wooller et al. (1990). In the absence of adequate data to determine otherwise, the mean, upper and lower limits for non-breeder survival (NBRS) were assumed to be equal to those for breeder survival (Table 1).

Survival rates were calculated for pre-breeders based on re-appearance rates of individuals banded as chicks (Table 2). Of the banded chicks known to have fledged from Fisher Island 42.3\% $( \pm 5.4 \%)$ returned to the island, on average, 4.158 $( \pm 0.135)$ years after their year of fledging (Serventy, 1967; Serventy and Curry, 1984). This equates to a ' $0-4$ year re-appearance rate' (probability of recovery of a live bird) from fledging to the beginning of year 4 of 0.437 ( \pm 0.033$)$. Ignoring birds that emigrated to other breeding populations, re-appearance probability in each of the first 3 years was estimated using the relative number of Short-tailed Shearwaters in each age class found dead (from recoveries of banded birds excluding those recovered at the breeding colony) as given in Table 5 of Serventy (1967). Using these ages at death as a $d_{x}$ schedule (Caughley 1977), one can estimate mean juvenile re-appearance rate (JR; the probability of re-appearance from fledg- ing to year 1), and probability of reappearance from year 1 to $2\left(\mathrm{PBR}_{1}\right)$, year 2 to year $3\left(\mathrm{PBR}_{2}\right)$, and year 3 to $4\left(\mathrm{PBR}_{3}\right)$ from:

$$
0.437=\mathrm{JR} \times \mathrm{PBR}_{1} \times \mathrm{PBR}_{2} \times \mathrm{PBR}_{3}
$$

Maximum survivals were calculated by assuming the upper confidence limit for the proportion returning and the upper average age of first arrival back at the colony. Conversely, minimum survival was calculated from lower confidence limits for the proportion returning and the age at first return (Table 2). The annual re-appearance rate of pre-breeders $>3$ years old was assumed to be equal to annual survival of breeding adults (Table 1). No formal estimate of the probability of detecting each bird if present on Fisher Island has been reported, but was assumed to be 1.0 because the island is small (0.8 ha) and was repeatedly searched each season (Serventy and Curry, 1984; Bradley et al., 1989; Wooller et al., 1990).

\subsubsection{Emigration}

Emigration was represented in the model as 1 - the annual probability of a pre-breeder staying on Fisher Island until it began breeding (PST). The mean estimate of the probability of staying was calculated as follows (Table 3):

1. the probability of re-appearance to the beginning of year 4 is $0.437(0.371-0.501$, Table 2$)$ giving an annual re-appearance probability of 0.769 (0.743-0.796); 
2. the average age of first breeding is 7.116 years ( \pm 0.213 , Bradley unpubl. data), therefore the average elapsed time between first re-appearance (Table 2) and first breeding is 2.958 $(2.610-3.306)$ years;

3. $0.14(0.118-0.164,95 \%$ binomial CI; Mainland et al., 1956) of 922 banded chicks were recruited to the breeding population on Fisher Island (Serventy and Curry, 1984), so the proportion of females that survive and stay from first re-appearance (Table 2) to first breeding can be estimated as $0.14 / 0.423=0.331$;

4. assuming that pre-breeders $>3$ years have the same survivorship as breeding adults (0.912; $0.901-0.923)$ the expected proportion surviving from first re-appearance to first breeding is $0.912^{2.958}=0.761 ;$ and

5. therefore $\mathrm{PST}^{2.958} \times 0.761=0.331$, which estimates a mean annual probability of staying (conditional on survival) of 0.755 . This represents the difference between the observed proportion of pre-breeders that stay and survive and the predicted proportion that survive based on adult survival rate.

The above calculation predicts that a mean of $24.5 \%$ of pre-breeding females emigrate each year to attempt to breed elsewhere (Table 3). The maximum probability of staying (minimum emigration) was calculated using the maximum period between arrival and breeding (lower confidence limit for average age at first arrival and upper confidence limit for age at first reproduction) and minimum survival through this period (lower CI on adult survival and upper $\mathrm{CI}$ on the proportion breeding; Table 3). Although the calculation of emigration rate involves a large number of assumptions, the apparent congruence with estimates calculated by Bradley et al. (1999) gives credence to its reliability.

\subsubsection{Immigration}

After an initial steady increase in the proportion of banded (known-age) breeders in early years of the study, the number of Fisher-Islandbred recruits in the breeding population has stabilized between 41 and $46 \%$ of all breeders (Serventy and Curry, 1984), with the stable level being reported as 45\% (Bradley et al., 1991). Accordingly the mean number of immigrants was set as $0.55 / 0.45=1.22$ times the number of natal pre-breeders of age 3 . The lower limit was set at $0.54 / 0.46=1.174$ and the upper limit at 0.59 / $0.41=1.439$ (Table 1$)$.

Table 3

Calculation of mean, maximum and minimum probability of staying to breed for Short-tailed Shearwaters on Fisher Island

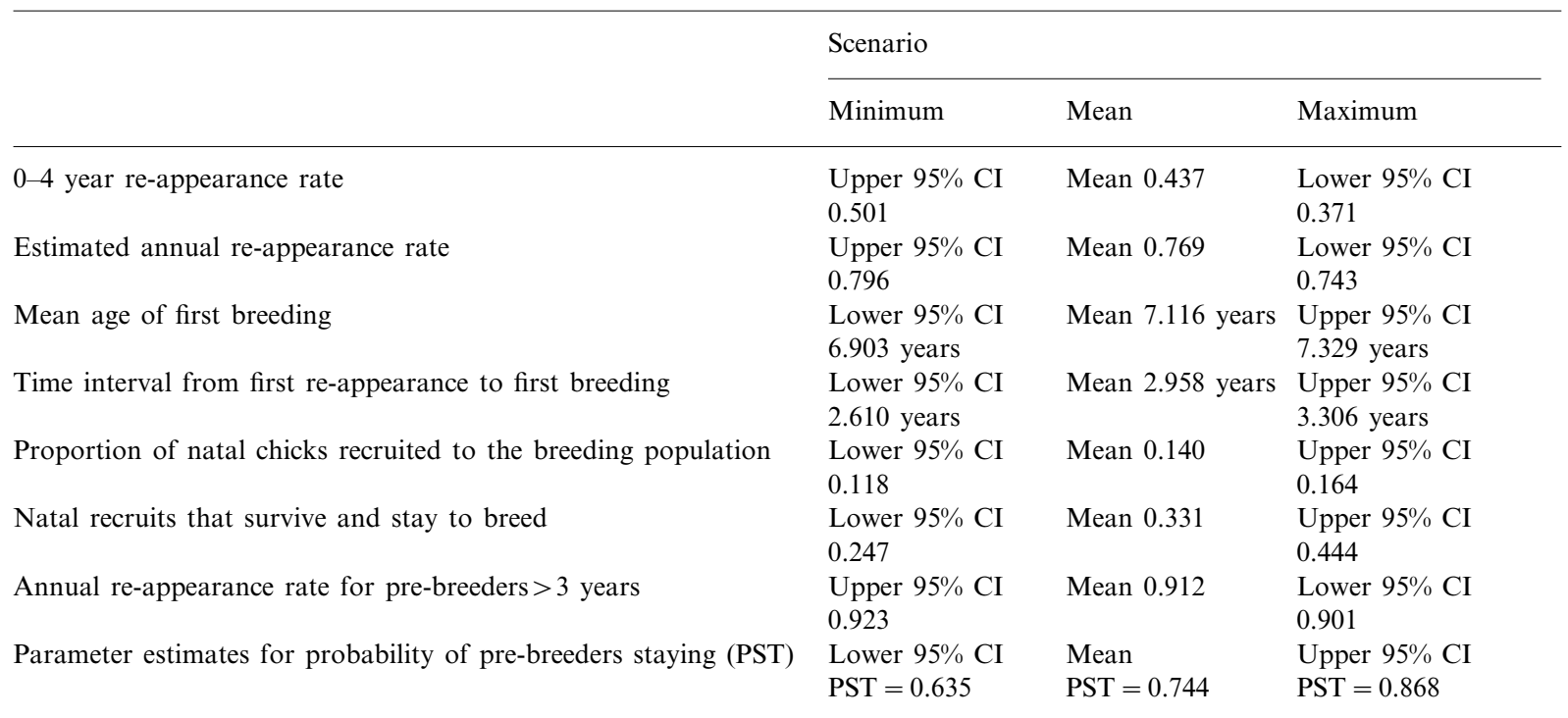




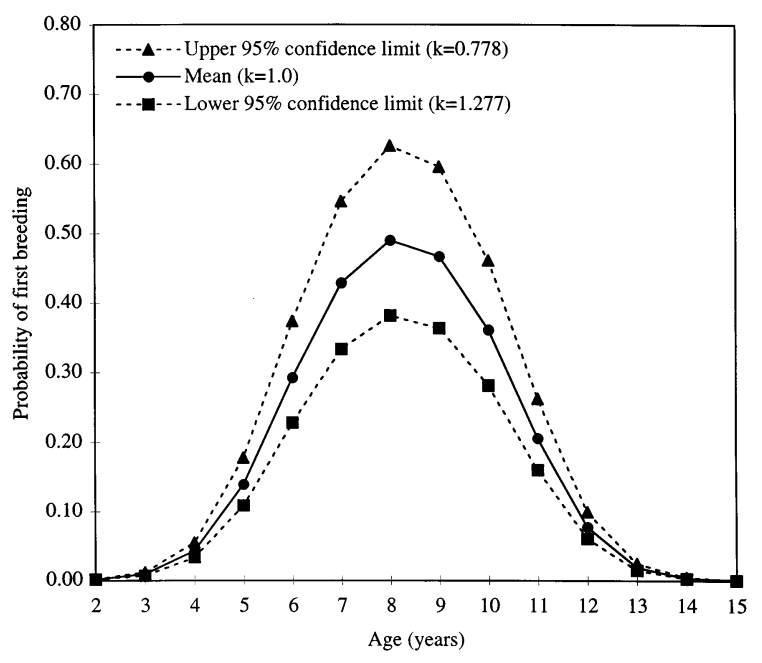

Fig. 3. Estimated probability of first breeding for mean, lower $95 \%$ confidence limit and upper $95 \%$ confidence limit of the probability of first breeding multiplier $(k)$ in the Average Breeder Model (ABM). Coefficients for equation one are those estimated for the mean values of all parameters $(a=-11.675$, $b=2.830$ and $c=-0.172$ ).

\subsubsection{Probability of first reproduction}

The probability of a bird of age $x$ breeding for the first time was modelled by a quadratic in $x$ on the logistic scale, i.e. $\log (p /(1-p))=a+b x+$ $c \times 2$ which is equivalent to:

$p=\left(1+\mathrm{e}^{-\left(a+b x+c x^{2}\right)}\right)^{-1}$

The logistic scale is commonly used for the statistical modelling of probabilities (Lebreton et al., 1992) and using a quadratic rather than a linear logistic equation imposes less restriction on the shape of the curve. An iterative procedure was used to solve for the coefficients $a, b$, and $c$ (using the SOLVER add-on in Excel), so that the proportion of first time breeders of age $x$ predicted from the model matched the observed proportion of first-time breeders of age $x$ on Fisher Island as closely as possible for the selected set of input parameters. This fit was achieved by choosing the values of the coefficients to be those that maximized the likelihood function of the observed proportions given by:

$L=\sum_{x=1}^{15} o_{x} \ln \left(p_{x}\right)$ where $o_{x}=$ the observed proportion of first time breeders of age $x$ from Fisher Island, and $p_{x}=$ the proportion of first time breeders of age $x$ output from the model.

Probability of first breeding at age $x$ was varied by multiplying $p$ (Eq. (1)) by a multiplier (Fig. 3). Upper and lower limits for the multiplier were calculated to give the same percentage change in the age of first breeding predicted by the model (using the mean values for all other parameters) as the $95 \%$ confidence interval for mean age of first breeding estimated for Fisher Island (Table 3; Bradley and Wooller unpubl. Data).

\subsection{Model simulations, parameter uncertainty and elasticity}

The initial population size for all simulations was set at 10000 . For each run of the model a set of input parameters was selected and the coefficients for Eq. (1) estimated. The stable age distribution was then calculated by running successive iterations of the model using the selected parameter values until the maximum discrepancy between the proportion of birds in any age class in two successive years was less than 0.001 . The coefficients for Eq. (1) were then re-estimated to correspond with the chosen stable age distribution. If the stable age distribution was not maintained with the new coefficients, the stable age distribution and the coefficients were recalculated in turn until the bound for the maximum allowable discrepancy in the stable age distribution was not exceeded. The model then simulated annual changes in each cohort for 50 years and the mean annual population growth rate $(\lambda)$ for the 50 years was calculated.

Each model was initially run with all parameters set to their mean values. The parameter uncertainty analysis was then performed by running each model 5000 times using a random number generator to independently select each input parameter from a uniform probability distribution between its minimum and maximum value (following McCarthy et al., 1995, 1996). Minimum and maximum values were set at the lower and upper $95 \%$ confidence limits for each parameter or multiplier. A multiple regression was used to 
relate the input parameters (Table 1) to population growth rate. Population growth rate was the dependent variable in the regression, with the independent variables including the 12 input parameters, all two-way interactions between these parameters (66 terms) and a quadratic term for each input parameter (12 terms). Quadratic terms were included to allow investigation of nonlinearities.

The multiple regression equation conveniently summarizes the model by combining the results of each set of simulations into a single equation that can be used to predict population growth rate for given input parameter values. Parameter uncertainty coefficients were calculated by estimating the difference between the predicted population growth rate when the minimum and maximum values (lower and upper 95\% confidence limits) of each parameter were substituted into the regression equation with all other parameters at their mean values. This difference was divided by the population growth rate predicted by the regression equation with all parameters set at their mean values:

coefficient $=$ absolute value $\left[\frac{\lambda\left(x_{\max }\right)-\lambda\left(x_{\min }\right)}{\lambda\left(x_{\text {mean }}\right)}\right]$

Elasticity coefficients for each parameter were estimated in the same way but the minimum and maximum values for each parameter were set at $\pm 5 \%$ of the mean estimate instead of the lower and upper $95 \%$ confidence limits. The relative width of the parameter ranges therefore differed from the parameter uncertainty analysis. The \pm $5 \%$ limits for all parameters in the elasticity analysis were close to or within the parameter space explored by the model simulation runs for the parameter uncertainty analysis, so running an additional set of model simulations and recalculating the regression equations was considered unnecessary. Elasticity coefficients were calculated for a set of minimum and maximum parameter limits estimated from $\pm 5 \%$ of mean mortality rates and $\pm 5 \%$ of mean survival rates.

Two-way interaction coefficients for each parameter were calculated by estimating the difference between the predicted population growth rate when the upper and the lower parameter values were substituted into the regression equation (with all other parameters at their mean values) divided by the predicted population growth rate for the mean parameter value. Unlike the basic elasticity and uncertainty coefficients, this change in population growth rate was calculated at each of the mean, minimum and maximum values of the second parameter in the interaction term. If no interaction existed between the two parameters, these three changes in population growth rate would be equal. Therefore the strength of the interaction was estimated as the absolute value of the difference between the change in population growth rate with the second parameter in the interaction term set at its minimum and at its maximum value (Eq. (4) and Table 4). Again, upper and lower limits for the parameter ranges were set at the $95 \%$ confidence limits for the parameter uncertainty analysis and $\pm 5 \%$ of the mean for the elasticity analyses.

interaction coefficient

$$
=\text { absolute value }\left[\frac{\left(\lambda_{C}-\lambda_{A}\right)}{\lambda_{B}}-\frac{\left(\lambda_{F}-\lambda_{D}\right)}{\lambda_{E}}\right]
$$

Table 4

Level of the first and second parameters used for calculating interaction coefficients in the elasticity and parameter uncertainty analyses

Level of first parameter

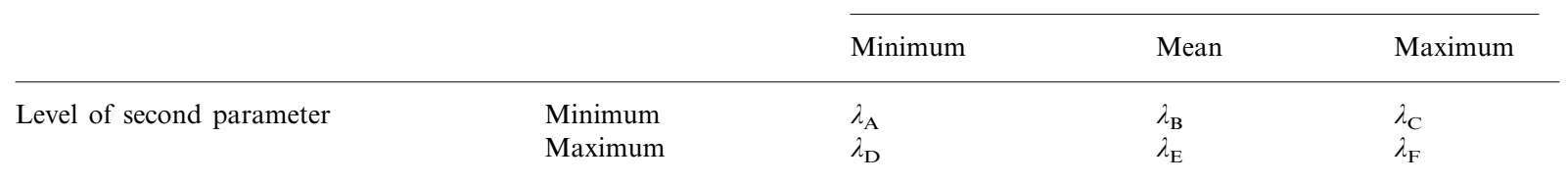




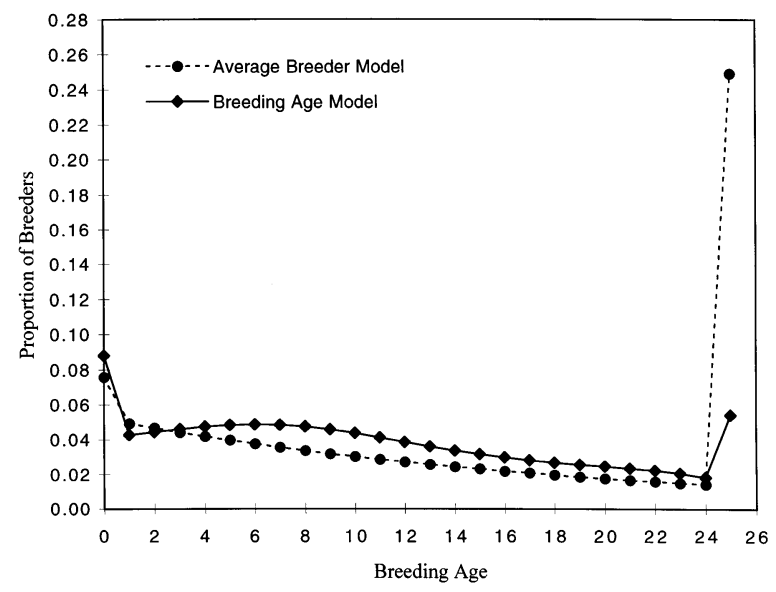

Fig. 4. Proportion of birds in each breeding age class for mean parameter input values in the Average Breeder Model (ABM) and the Breeding Age model (BAM).

\section{Results}

\subsection{Model comparison}

Predicted population growth rate for both models (0.963 and 0.948 for the ABM and BAM, respectively) using the mean estimates for all parameters were lower than the population growth rate observed on Fisher Island (0.9800.992). As expected, assuming a single adult survival rate (ABM) led to a positive bias in population growth, a result of maintaining a higher survival and breeding success at older ages. This bias is demonstrated by the unrealistically high proportion of breeders $\geq 25$ years (Fig. 4) and mean life expectancy after first breeding (14.0 years) in the ABM compared to the BAM (10.1 years). All known-age birds on Fisher Island were dead 27 years after first breeding and the observed life expectancy after first breeding was 9.3 years (Wooller et al., 1989). The lower population growth rate predicted by the BAM model was a result of the lower mean breeding success and breeder survival rates predicted by the breeding age equations. Setting the multipliers for these equations to values that predicted weighted means equivalent to the mean values used in the ABM raised the population growth rate for the BAM to 0.969. The BAM appears to provide a better representation of the demographic structure of the population although population growth rate predicted by both versions of the model appears to be low.

\subsection{Parameter uncertainty coefficients}

A high $R^{2}$ (0.99992 and 0.99999 for the ABM and BAM respectively) for the regression equations for both models showed a good fit to the data and indicates the completeness of the regression equations in summarizing the models. The residual standard deviations, which predict how far most points will be from the regression equation, were 0.00013 and 0.00003 for the ABM and the BAM, respectively. Ninety-five percent of simulated population growth rates should be within \pm 2 residual standard deviations of population growth predicted by the regression equation. Plots of the residuals versus each input parameter indicated the assumptions of normality and equality of variances for the regression analyses were valid. Estimates of the regression coefficients are given in Appendix A.

A ranking of the parameter uncertainty coefficients shows the relative importance of errors in parameter estimation to predicting population growth rate. Parameter uncertainty coefficients were very similar in both order and magnitude between the two models. Probability of pre-breeders staying in the colony had by far the strongest potential to influence population growth rate in both models, with an uncertainty coefficient five times higher than the second ranked parameter (Table 5a). Even parameters such as probability of first breeding and probability of breeders skipping, which ranked very low, may have non-trivial effects on population growth rate projections based on the magnitude of the uncertainty coefficients.

To examine the effect of the lower mean breeding success, breeder survival, and skipping rates estimated by the breeding age equations in the $\mathrm{BAM}$, the multipliers were adjusted to give the equivalent mean, minimum and maximum values used in the $A B M$ and the parameter uncertainty coefficients were recalculated. This had virtually no effect, the importance of probability of staying was 


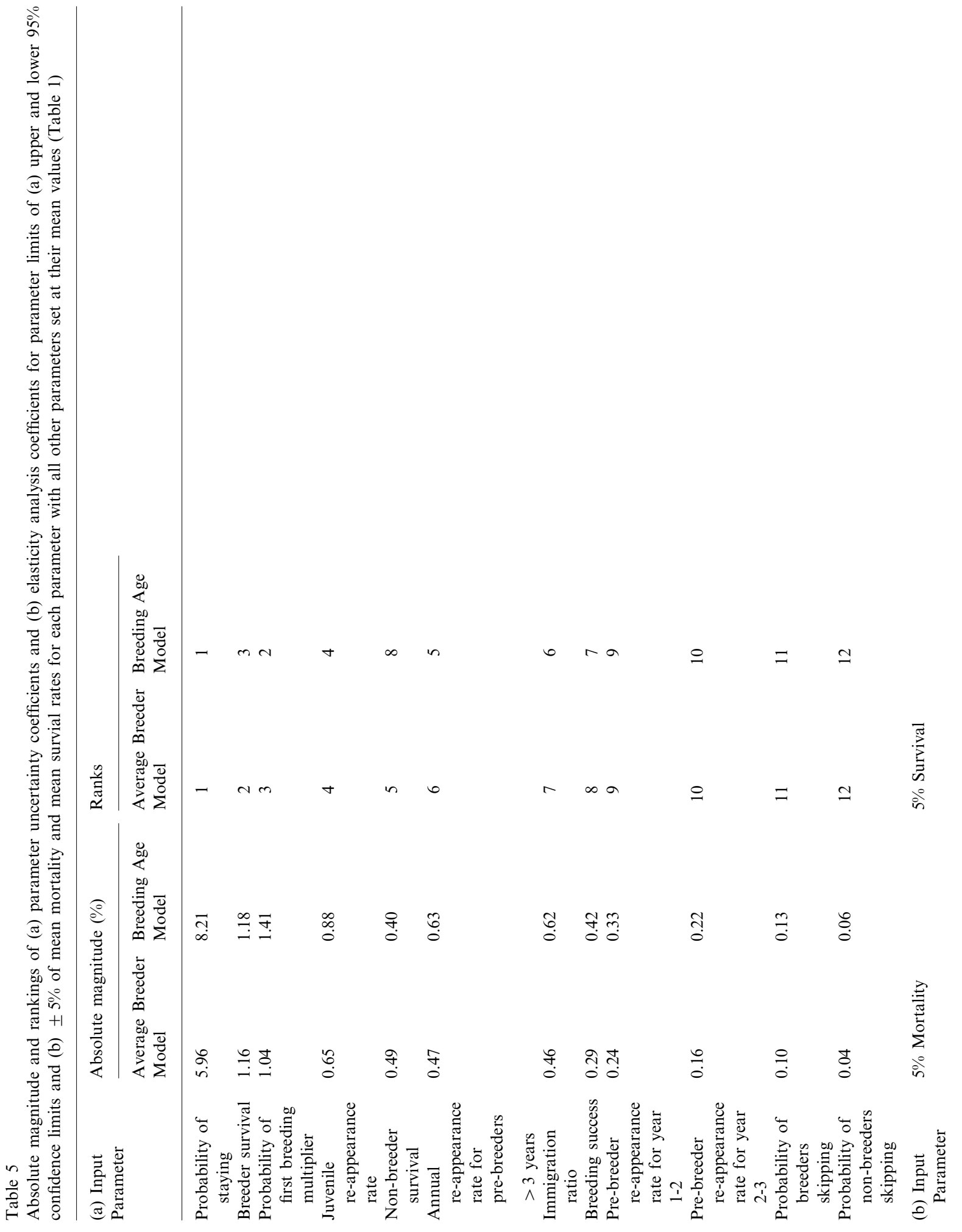




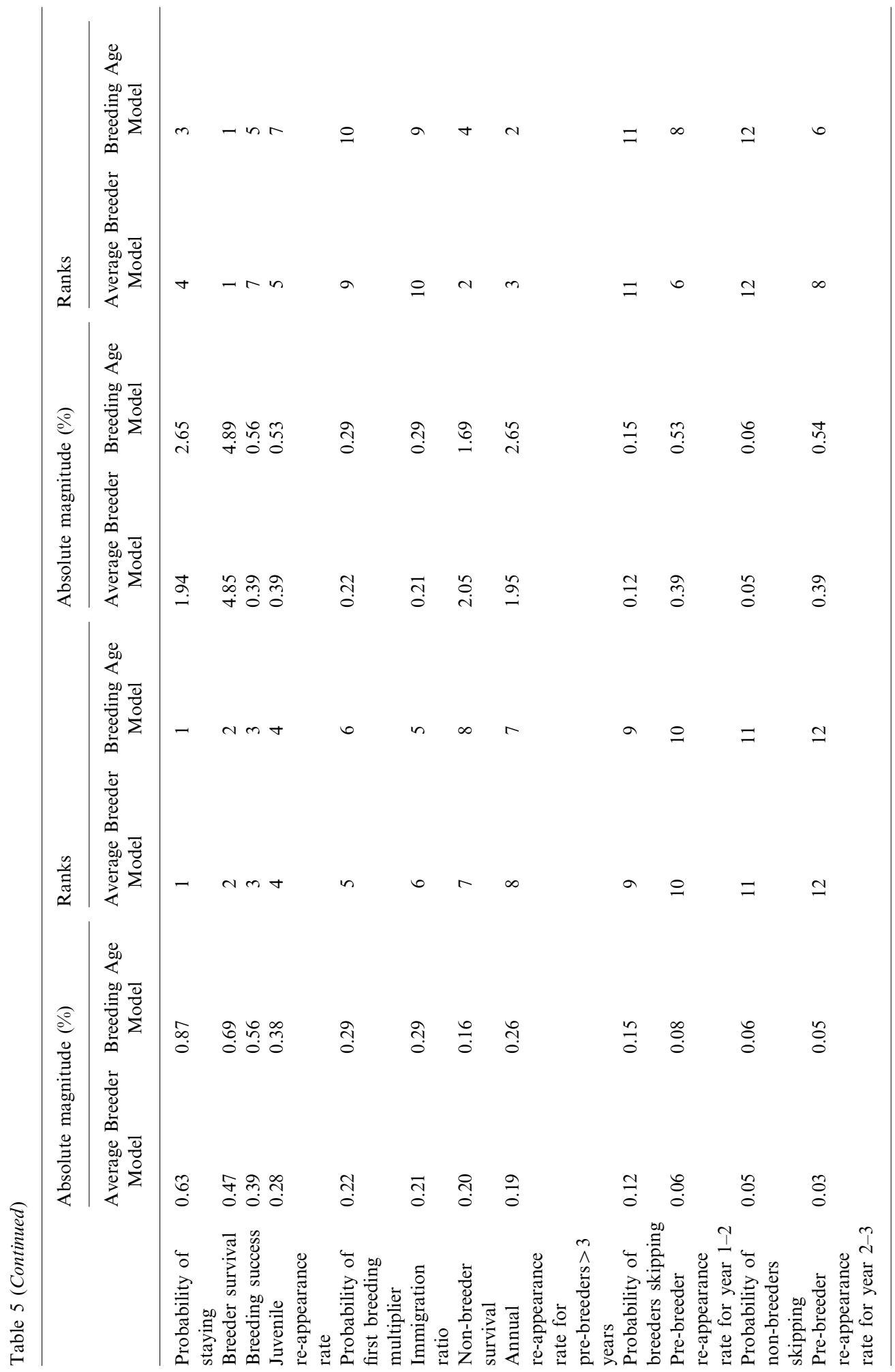


Table 6

Absolute magnitude of interaction coefficients in parameter uncertainty analysis for the Average Breeder Model ${ }^{\mathrm{a}}$

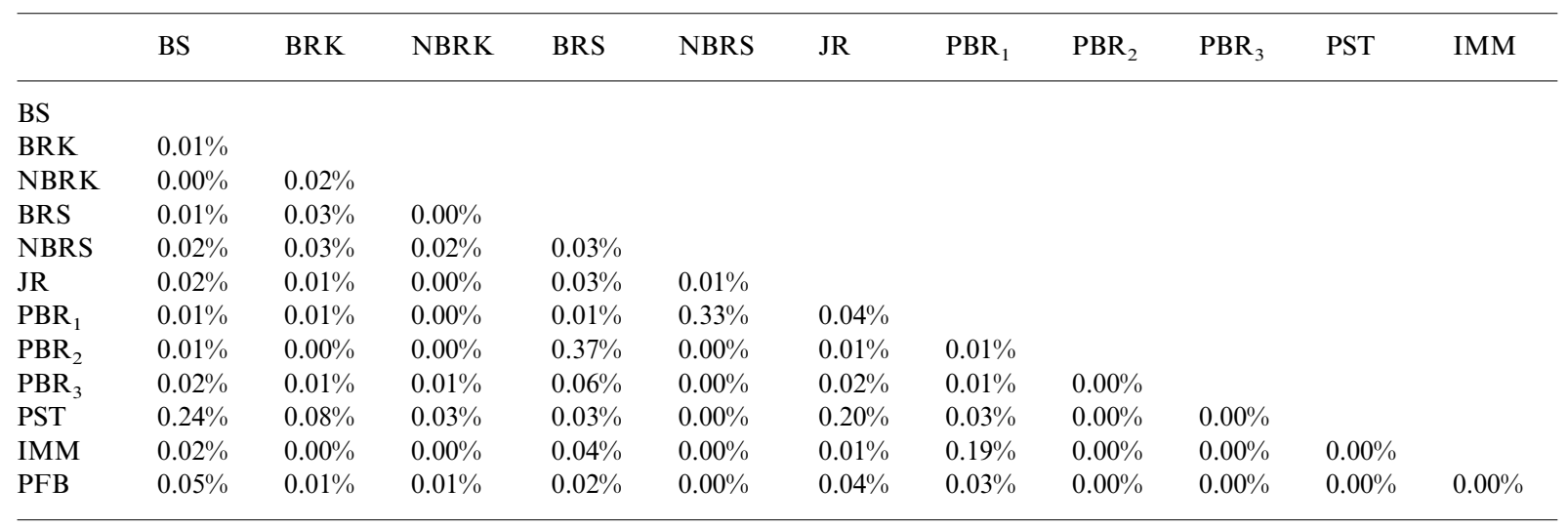

a The magnitude of all interactions coefficients were smaller in Breeding Age Model.

increased by $0.23 \%$ but all other parameters changed by less than $0.05 \%$. All parameters maintained their original rankings.

\subsection{Elasticity coefficients}

Results for the elasticity analyses using $\pm 5 \%$ of mean mortality and $\pm 5 \%$ of mean survival rates were very different, both from each other and from the parameter uncertainty analysis (Table $5 \mathrm{a}-\mathrm{b}$ ). Using $\pm 5 \%$ of mean mortality rates greatly reduced the importance of the probability of staying, although it still ranked second, and increased the importance of probability of first breeding and breeding success. Using $\pm 5 \%$ of mean survival rates resulted in a dramatic increase in the relative importance of survival rates, particularly breeder survival, non-breeder survival and re-appearance rate of pre-breeders $>$ 3 years. The relative magnitude and rankings of coefficients for both elasticity analyses were similar for the ABM and BAM.

\subsection{Interaction coefficients}

A large number of interaction terms were statistically significant in the regression equation (41 and 37 for the ABM and BAM, respectively; Appendix A). In general, the influence of interaction terms was low, indicating a likely lack of biological significance for most, if not all, interac- tions for the parameter space were explored (Tables 6 and 7). For the parameter uncertainty analysis 52 and $70 \%$ of interactions in the ABM and BAM, respectively, were $<0.01 \%$, and only 12 and $9 \%$, respectively, were $>0.05 \%$. In general the strength of interaction terms was lowest in the elasticity analysis using $\pm 5 \%$ of mean mortality rates, which explored the smallest parameter space, and highest in the elasticity analysis using $\pm 5 \%$ of mean survival rates which explored the largest overall parameter space (Table 7).

\section{Table 7}

Percent of interaction terms $<0.01 \%$ and $>0.05 \%$ for the Average Breeder Model and the Breeding Age Model in the parameter uncertainty and $\pm 5 \%$ mean mortality and $\pm 5 \%$ mean survival elasticity analyses

\begin{tabular}{|c|c|c|c|}
\hline \multirow[t]{2}{*}{ Analysis } & & \multicolumn{2}{|c|}{ Interaction strength $(\%)$} \\
\hline & & $<0.01$ & $>0.05$ \\
\hline \multirow{3}{*}{$\begin{array}{l}\text { Parameter } \\
\text { uncertainty }\end{array}$} & Average & 52 & 12 \\
\hline & Breeder Model & & \\
\hline & $\begin{array}{l}\text { Breeding Age } \\
\text { Model }\end{array}$ & 70 & 9 \\
\hline \multirow[t]{2}{*}{ $\pm 5 \%$ Mortality } & Average & 86 & 0 \\
\hline & $\begin{array}{l}\text { Breeding Age } \\
\text { Model }\end{array}$ & 94 & 0 \\
\hline \multirow[t]{2}{*}{ $\pm 5 \%$ Survival } & $\begin{array}{l}\text { Average } \\
\text { Breeder Model }\end{array}$ & 45 & 27 \\
\hline & $\begin{array}{l}\text { Breeding Age } \\
\text { Model }\end{array}$ & 67 & 12 \\
\hline
\end{tabular}




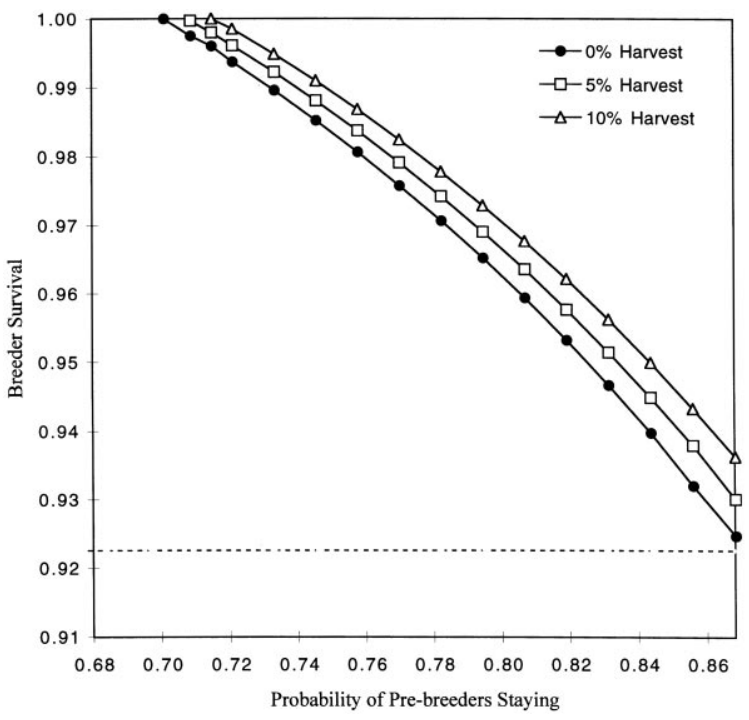

Fig. 5. Breeder survival vs. probability of pre-breeders staying in the natal colony for population growth rate equal to one and harvest rate $=0,5$ and $10 \%$ with all other parameters at their mean values for the Average Breeder Model (ABM). Population growth rate is greater than 1 for areas above and to the right of the line for $0 \%$ harvest rate, and decreasing for areas below and to the left of the line for $0 \%$ harvest rate.

The strongest interaction in the parameter uncertainty analysis, the interaction between breeder survival and re-appearance rate of pre-breeders from year 2-3, showed a difference of only 0.37 and $0.17 \%$ in the $\mathrm{ABM}$ and BAM, respectively. The potential effect of this interaction can be illustrated as follows; the mean influence of breeder survival on population growth rate is $1.16 \%$ for the $\mathrm{ABM}$, this can increase to $1.16+$ $0.37=1.53 \%$ at the maximum level of $\mathrm{PBR}_{2}$ or decrease to $1.16-0.37=0.79 \%$ at the minimum level of $\mathrm{PBR}_{2}$. Thus interactions can cause predictions of population growth rate for a given parameter level to change depending on the level of the interacting parameter. The relative importance of interactions may be greater for parameters with low individual elasticity or uncertainty coefficients but high interaction coefficients. For example, the influence of breeding success may vary from 0.05 to $0.53 \%$ depending on the level of probability of staying. This is a greater percentage change than illustrated above for breeder survival, although the interaction coefficient for these two parameters $(0.29 \%)$ is lower.
Quadratic terms were included in the regression equation to evaluate the importance of non-linearities. The strength of non-linearities were assessed by comparing the change in population growth rate (as predicted by the regression equation) when going from the lower to the mean value of each parameter with the change when going from the mean to the upper value. This was akin to the assessment of interaction strengths. In no case, for both the uncertainty and elasticity analyses, did the difference in these changes exceed $0.0006 \%$, implying that any non-linearity in the model was weak.

\subsection{Harvest scenarios}

A parameter, $H$, was defined as the proportion of fledged chicks that were harvested. Since the regression equation can be used to predict changes in population growth rate from varying parameter values, one can predict the effect of different harvest scenarios by varying $H$. By setting the regression equation equal to one and allowing two parameters to vary simultaneously (with all other parameters set at their mean values), one can define the parameter space which represents an increasing or decreasing population (Fig. 5). No combination of values within the 95\% confidence limits for any two parameters led to an increasing population. However, varying probability of pre-breeders staying within its $95 \%$ confidence limits and allowing breeder survival to vary freely shows that an increasing population could potentially be achieved if breeder survival was above 0.928 (ABM; Fig. 5).

Harvest can be imposed on the population by setting $H>0$ and recalculating the new parameter values necessary to maintain a population growth rate of one (Fig. 5). The position of the lines for $H=0 \%, H=5 \%$ and $H=10 \%$ outside the expected parameter space on Fig. 5 implies that no level of harvest could be sustained on Fisher Island. However, these lines illustrate the utility of the regression equation for predicting the shift in population growth rate that would be expected by imposing harvest, or to illustrate the change in a parameter that would be necessary to compensate for a specified harvest level. 


\section{Discussion}

\subsection{Model structure and validity}

The structure of the model reflects the understanding of what is ecologically important in Short-tailed Shearwater population dynamics and the practicalities of seabird research. Model structure was chosen to reflect the results of the Fisher Island study that demonstrate considerable variation in breeding success (Fig. 2a), probability of skipping breeding (Fig. 2b) and mortality (Fig. 2c) with breeding age (Wooller et al., 1988, 1990; Bradley et al., 1989, 1991). It mixes a classic age-structured approach for pre-breeders with breeding age cohorts for fecund birds. Breeding age is roughly correlated with actual age, but breeding age explains more variation in reproductive rates than does age per se. Significant increases in breeding success with age among birds first breeding between 5 and 9 years were found but there was no evidence that such age dependent differences persisted beyond the first breeding attempt (Wooller et al., 1990).

Over-parameterization of preliminary models is strongly discouraged by many authors (Beck, 1983; Starfield and Bleloch, 1986; Burgman et al., 1993; Starfield, 1997). Although incorporating breeding age specific data on survival, breeding success and skipping rates resulted in a relatively complex demographic model, of interest was in assessing whether the 40-plus years of age-specific data would be useful for improving the understanding of Sooty Shearwater populations. The result was a closer approximation to the demographic structure of the Fisher Island population (Fig. 4), suggesting the additional data would be useful for answering questions such as the influence of density dependence on the ratio of nonbreeders to breeders in the population. However, the similarity of results for the parameter uncertainty and elasticity analyses (Table 5a-b) indicates that the additional model structure is unnecessary for setting research priorities or assessing the relative effects of alternative management strategies.

Incorporating age structure of pre-breeders in a model requires estimating the probability of breeding for the first time at age $x$. As far as is known, this has not been estimated directly for any procellariiforme. Direct estimation requires knowledge of the number birds of each age available and trying for the opportunity to breed each year in addition to the actual age of birds that breed for the first time. Empirical studies usually only report the proportion of first time breeders of age $x$ and/or the mean age of first breeding. However, these parameters represent output of an age- or stage-structured model, not input. Lack of information on the number of birds present and available to breed forced the use an iterative process to set first breeding probabilities so that the probability of first time breeders being of age $x$ predicted by the model matched the observed distribution. There is no way of knowing how well constraining variability in age of first breeding translates to the true variability in probability of first breeding, or of validating the form of Eq. (1). Procellariid researchers are urged to measure the number of birds of age $x$ trying the gain entry to the breeding population in addition to the number that succeed for each age $x$ if possible. Reporting just the latter will continue to make it difficult to parameterize models incorporating age structure of pre-breeders.

In contrast to the model predictions, the empirical evidence from Fisher Island suggests relative stability over the last 20 years. One expects the difference comes from both: (i) a lack of density dependence in the model (there is evidence of this for recruitment rates in other seabirds; Weimerskirch and Jouventin, 1987; Pickering, 1989; Brooke, 1990; Croxall et al., 1990); and (ii) estimation of parameters from data that spanned two apparently different demographic phases, a rapid decline from 1947 to 1975 followed by a period of relative stability from 1976 to the present. Published data from Fisher Island is presented only for the combined period of these two phases so it was not possible to calculate separate parameter estimates for the first and second phases. The contrast in population trajectories between the two phases (Serventy and Curry, 1984; Bradley et al., 1991) suggests a change in external influences or in the fundamental level of one or more demographic parameters. Model results assume condi- 
tions under which predictions are made remain constant, which will be invalid unless parameters can be re-estimated separately for each of the two phases. Since one cannot factor out the initial decline, population growth rates predicted by the model are expected to be lower than the current growth rate of the population.

Two additional sources of bias that could have resulted in low estimates of population growth rate are present in the calculations of emigration and re-appearance rates of pre-breeders. For simplicity, and due to the lack of data for alternative calculations, a constant emigration rate was assumed from the time of first return to first breeding or death. However, Short-tailed Shearwaters appear to become more faithful to a colony during their prospecting period (Bradley et al., 1999) and it is likely that with increasing investment in prospecting at a given colony the probability of emigrating decreases. A decreasing probability of emigration would therefore be roughly correlated with age. If real, failure to incorporate this decline in the model would negatively bias population growth rate estimates.

The estimates of re-appearance rates for prebreeders assumed the probability of detection of pre-breeders attending the colony was equal to 1 (Table 3). A maximum likelihood estimation of the probability of missing a pre-breeder, assuming that pre-breeders not seen in years subsequent to actual sightings were missed birds, suggests this probability of detection may be as low as $70 \%$ (Bradley et al., 1999). This would cause the prebreeder survival estimates to be biased low and age of first breeding estimates to be biased high. Thus resulting in negatively biased population growth rates. A corresponding probability of detection $<1$ is unlikely to have occurred for breeders as great care was taken throughout the study to record all birds inhabiting burrows with eggs, with multiple checks made each breeding season (Bradley et al., 1999). Colony attendance of breeders is also less sporadic and less seasonally restricted than attendance of pre-breeders. It may be possible to minimize biases caused by detection probabilities $<1$ by re-analyzing colony attendance data using modern mark-recapture techniques (Lebreton et al. 1992).

\subsection{Short-tailed Shearwater demography}

Modelling provides a framework for formalizing concepts about the dynamics of populations and helps to highlight where important knowledge is missing. The parameter uncertainty analysis identified probability of staying and juvenile reappearance rate as the parameters that provide the greatest opportunity to improve the accuracy of the population growth rate estimates (Table 5a). Probability of staying affects a large proportion of the population, $26 \%$ of pre-breeders (Table 1) are lost from each of 12 stages in contrast to less than $9 \%$ lost due to mortality. However, the uncertainty in population growth rate depends not only on the mean level of a parameter and the proportion of the population it influences but also on the degree of uncertainty in estimating the parameter, which is reflected in the width of the parameter range. Probability of staying, or its converse emigration rate, is one of the most difficult parameters to estimate for highly mobile, widely dispersed animals such as seabirds. This resulted in a parameter range of $\pm 16 \%$ of mean probability of staying $( \pm 46 \%$ of mean emigration), nearly twice that of any other parameter.

Breeder survival, commonly established as the most influential parameter for models of longlived vertebrates (Goodman, 1980; Brault and Caswell, 1993; Weimerskirch et al., 1996; Crook et al., 1998; Heppell, 1998; Russell, 1999; Heppell et al., 2000; Slooten et al., in press) was an important factor in both the elasticity and parameter uncertainty analyses (Table 5a-b). However, the combined importance of prebreeder survival rates was similar to or greater than the combined importance of fecund bird survival rates. The importance of all pre-breeder survival rates combined, calculated by summing the parameter uncertainty coefficients for JR, $\mathrm{PBR}_{1}, \mathrm{PBR}_{2}$ and $\mathrm{PBR}_{3}$, were 1.52 and $2.06 \%$ (for the ABM and BAM, respectively). In contrast, the importance of fecund bird survival rates (BRS and NBRS) were 1.65 and $1.58 \%$ (ABM and BAM, respectively, Table 5a). The lower relative importance of fecund survival rates in the BAM is likely a result of the low survival rates predicted by the polynomial for higher ages. Although these 
results differ between the two models, both models demonstrate that large gains in the precision of population growth rate estimates can be made from reducing variability in pre-breeder survival rates as well as in survival rates of fecund birds. The lack of precise data on survival rates for most procellariiformes reflects the logistical challenges faced in the field. The estimation of migration rates and survival rates of pre-breeders are particularly challenging and it is often difficult to distinguish between the two. Vast population sizes, large numbers of neighbouring colonies, an often high degree of inter-colony movement and a broad range of ages over which young birds return to the colony and begin breeding all contribute to the difficulties in obtaining accurate, unbiased estimates.

Results for the elasticity analysis using $\pm 5 \%$ of mean mortality rates to calculate parameter ranges were similar to a sensitivity analysis of a stochastic PVA model investigating impacts of harvest and predation on Sooty Shearwaters (Hamilton and Moller, 1995). Using $\pm 10 \%$ limits ( \pm 1 year for age of first breeding, which was constrained to a whole number, was equivalent to $\pm 17 \%$ ) Hamilton and Moller (1995) found that age at first breeding had the greatest effect on population growth rate, followed by $0-1$ year mortality (breeding success and juvenile mortality). Sensitivity and elasticity analyses identify parameters that will effect the greatest change in population growth rate for a unit or percentage change in a parameter. These methods identify parameters that are likely to produce the greatest population response if altered by management. Unfortunately neither probability of first reproduction nor probability of staying lend themselves to simple manipulation by management. In this case managers may need to accept the lesser gains but increased practicality of altering parameters such as juvenile survival, breeder survival or breeding success.

The long-term study on Fisher Island enabled estimation of parameters with reasonable accuracy, but because the parameter estimates are specific to this population, the results are also only applicable to Fisher Island. This is especially true for emigration and immigration rates, two very site-dependent parameters that are probably influenced not only by local density on Fisher Island, but also by the distance to, and size of, surrounding breeding colonies. Emigration and immigration rates may be expected to be more variable among populations than survival and reproductive rates, which are more constrained by bio-energetics and biophysical characteristics for long-lived species such as shearwaters. The small size of the Fisher Island population, which represents one extreme of a very wide range of colony sizes, makes extrapolation of the results to other populations questionable without some measure of how typical the demographics of this population are compared to other colonies.

\subsection{Harvest scenarios}

As far as the authors are aware, there are no plans to begin harvesting Short-tailed Shearwater chicks on Fisher Island. The point in estimating a sustainable harvest level for this population is simply to demonstrate the potential use of modelling to evaluate harvest impacts. The structure of the model assumes there is no density dependence and that mortality and harvest are independent (i.e. that harvest impacts are additive). Density dependence or compensatory effects between harvest and mortality would shift the lines representing a stable population $(\lambda=1)$ for different harvest levels on Fig. 5 down and to the left, representing a reduction in the impact of harvest for any given level of breeder survival or probability of staying.

Norman (1985) found that a simple deterministic model using parameter estimates for Fisher Island showed a harvest level of $10 \%$ of chicks would cause a slowly increasing population to decline to $53 \%$ of its original size in 100 years. In contrast, Skira et al. (1986) present a first approximation to a maximum sustainable yield calculation for harvest of Short-tailed Shearwater chicks of $37 \%$. However, these estimates are based on a very high expectation of breeding life (15 years) and recruitment rate $(0.35)$. Substituting a mean breeding age of 9.3 into their equation produces a declining population from which no sustainable harvest is possible. Immigration, density depen- 
dence and compensatory mortality are not included in the calculations of Norman (1985) or Skira et al. (1986). Harvesting on commercial colonies is estimated to be $<30 \%$ but on noncommercial colonies may be as high as $90 \%$ (Skira et al., 1986; Skira, 1990). Clearly the persistence of colonies under these levels of harvest demonstrates that at least some populations are able to cope with (although possibly through high immigration) what appear to be quite high levels of harvesting. Again, the inability to withstand harvesting predicted by Norman (1985), this model and the revision of the calculations of Skira et al. (1986) is likely a result of estimating parameter inputs from a small, possibly declining population. Knowledge of the variability of parameters among populations is needed before reliable estimates of the impacts of harvest elsewhere can be made.

\subsection{Multiple regression approach to parameter uncertainty and elasticity analyses}

Summarizing the results of a large number of simulations using a regression equation, which can then be used to predict the effects of changes in parameter values on population growth rate, provides a straightforward, comprehensible method for estimating parameter elasticity and uncertainty coefficients. Assuming the regression equation provides a reasonably accurate representation of the model, predicting population growth rate using the regression equation should be equivalent to direct substitution in the model. The regression equation offers the advantage of simpler and faster computation and allows the importance of both individual parameters and interactions to be described using a relatively small number of simulations $(5000$ for each model). This method would also allow direct comparison of results from deterministic and stochastic models by eliminating the need to run multiple simulations for direct substitution in a stochastic model.

The multiple regression equation, which initially may seem complex and overparameterized, could have been simplified by eliminating non-significant terms. However, the usual justification for reducing a regression equation is to trade off increased bias for smaller standard errors of the estimates. With such a large data set this results in little real gain. Additionally, one is most interested in the completeness of the regression equation in describing the model so the statistical significance of terms is of less importance than in more traditional uses of regression analyses. Statistical significance ( $P$-values), the usual measure of the importance of regression terms, is a function of sample size which in this case is arbitrary and very large because a large data set is being summarized. While parameters with a large influence on population growth are still expected to be more significant than less important parameters, in this context statistical significance is not necessarily meaningful. Non-significant results may be more useful in that they indicate terms that are clearly not important.

Randomly sampling from uniform distributions has the disadvantage of selecting a large number of parameter observations close to the mean. Only half of the observations would be expected to be closer to the tails of the distribution than to the mean, somewhat less than the theoretical optimum for estimating a linear regression. Having the tails of the distribution less well explored may result in a less precise regression equation and subsequently less precise estimates of the uncertainty or elasticity coefficients (Swartzman and Kaluzny, 1987). A factorial design using two levels for each of the 12 parameters would achieve greater precision for a smaller number of runs $\left(2^{12}=4096\right)$ by sampling from the extremes of the parameter ranges. However, only sampling at two levels of each parameter does not allow for evaluating the importance of interactions or non-linearities. A factorial design using three levels of 12 parameters, the minimum necessary to assess interactions, would require $3^{12}=513441$ model runs, a rather daunting proposition. Other options such as latin hypercube sampling (modified Monte Carlo sampling) may allow for more complete sampling of the tails with fewer simulations but at a cost of more complex programming (Iman and Helton 1988). The random sampling procedure sacrifices precision for simplicity while still allowing for the assessment of interactions 
and non-linearities with a reasonable number of simulations.

A great advantage of summarizing the model with a multiple regression equation is the ability to rigorously explore the effects of interactions. Although the majority of interactions were small it is worth noting that some, for example BRS $\times$ $\mathrm{PBR}_{2}$ (Table 6), had as large an effect on population growth rate as some individual parameters. Parameterization of the model specific to the Fisher Island population resulted in relatively narrow parameter ranges, which may have reduced the possibilities for interactions and non-linearities to occur. Using a parameter range of $\pm 5 \%$ of mean survival resulted in a larger number of stronger interactions, most likely as a result of the larger parameter space explored (Table 7). In populations with greater uncertainty in parameter estimation, and therefore a larger parameter space, interactions may be more prevalent. Although interactions had only a limited effect on population growth rate in this case, their inclusion in evaluating parameter elasticities and uncertainties is no less important. Strong interactions or non-linearities can change the effect and interpretation of individual parameters. For example, if elasticity predicts $x$ to be the key parameter and $y$ (low elasticity by itself) is not measured the final outcome may still be uncertain if the interaction $x y$ is important. Researchers are encouraged to evaluate the influence of interactions when conducting perturbation analyses to prevent simple univariate approaches from being misleading.

\subsection{Elasticity versus parameter uncertainty analyses}

Parameter uncertainty analysis, as has been defined here, is critically dependent on the validity of the limits set for the parameter ranges. The reliability of parameter ranges will be influenced by the availability of field data and the approach used for estimating parameter uncertainty. There is often an intuitive wish to cover the options and set 'safe' limits for relatively unknown parameters such as juvenile survival and emigration. This can easily result in setting unreasonably wide or arbitrary limits, which may produce misleading results and increase the importance of non-linearities. However, when little data are available this is still likely to be a useful first step. Wide limits set for unknown parameters will still reflect the relative knowledge of them, albeit exaggeratedly. Parameter limits estimated from degree of variability will always be more dependent on sample size than limits based on measures of central tendency.

The scale over which parameters are estimated, for example a single population, across a species geographic distribution, or including congeneric species, affects the type and amount of variation included in parameter estimates. As more variation is included in parameter estimates, parameter ranges estimated for a parameter uncertainty analysis become wider. This is likely to affect some parameters more than others as parameters for demographic models are usually estimated at a combination of scales and for a poorly defined mix of spatial, temporal, sampling and measurement variation. For example, Hamilton and Moller (1995) combine data from Sooty Shearwaters, Short-tailed Shearwaters and Manx Shearwater (Puffinus puffinus) in a population viability model to asses the sensitivity of Sooty Shearwater colonies to predation and harvest. Similarly, data from a single population is combined with data from all New Zealand populations and congeneric species in Slooten et al. (in press), to examine the effects of uncertainty in parameter estimation on demographics of Hector's dolphins (Cephalorhynchus hectori). The importance of parameters estimated at more global scales is likely to be increased as a result of including more types of variation. Again, this should still reflect knowledge of the parameters concerned, as one is usually forced to look elsewhere for parameters which there is little data for. Mixing levels of estimation can make interpretation of model results confusing and should be acknowledged. The objectives of a modelling exercise are extremely important in deciding how to parameterize the model.

Elasticity analysis conveniently bypasses these problems but presents some of its own. The degree by which parameters are varied, for example 5 or $10 \%$, is purely arbitrary. If non-linearities or interactions occur, the choice of this level will 
affect the elasticity coefficient rankings. The question of whether to vary survival or mortality rates, a seemingly minor and often ignored point, can also have a dramatic effect on elasticity analysis results (Table 5b). Few studies explicitly state whether survival or mortality rates are altered. By convention survival rates are usually referred to, so should one assume that if not explicitly stated it is survival that is being altered? Altering survival and mortality rates by the same percentage results in very different parameter ranges and is reflected in different elasticity rankings. The importance of survival rates will always be heightened in elasticity analyses altering survival rather than mortality rates. This is an inevitable outcome of manipulating proportions, as a proportion closer to 1 will always have a wider relative parameter range when adjusted by a specified percentage. For example, a mean survival rate of $0.90 \pm 5 \%$ of survival gives a parameter range of $0.855-0.945$, whereas $\pm 5 \%$ of mortality gives a parameter range of $0.895-0.905$, a 10 -fold difference. This may partly explain the commonly observed pattern of identifying adult survival as the most influential parameter in sensitivity and elasticity analyses of long-lived vertebrates.

The elasticity and parameter uncertainty analyses have different interpretations because of the different methods used to set limits for the parameter ranges. However, they should not be considered as competing methods for evaluating the influence of parameters on model outcomes. The different interpretations are useful for answering different questions. Parameter uncertainty analysis provides one with an insight into which parameters contribute most to variation in model outcomes. It therefore identifies where research efforts should be focused to make the greatest gains in the precision of model outcomes. By contrast, elasticity analysis shows to what degree model outcomes can be expected to respond to specified increases or decreases in mean parameter values. Elasticity coefficients therefore identify which parameters management efforts should focus on to achieve the greatest gains in model outcomes such as population growth (de Kroon et al., 2000; Caswell, 2000).
In assessing the results of either elasticity or parameter uncertainty analyses it is important to consider what biological changes are reasonable. Elasticity analyses only identify what the potential effect of a change in parameter levels is on model output (Caswell, 2000; de Kroon et al., 2000; Wisdom et al., 2000). If management cannot alter a given parameter, then no matter what the potential gains, that potential can never be realized. Sooty Shearwaters lay only one egg, so although there may be great theoretical gains to raising two offspring this would not be a useful management goal. Similarly, parameter uncertainty analysis identifies only where the greatest gains in reducing the variability in population growth rate can be made, it says nothing about how achievable those gains will be. It is likely to be logistically more challenging and more costly to reduce variation in estimates of emigration rates and juvenile survival than of breeding success or adult survival. Elasticity and parameter uncertainty analyses identify potential management or research targets but say nothing about the feasibility of achieving those targets.

An advantage of simulation over analytic models is that they allow the alternative of evaluating specific management options. Rather than adjusting parameter levels by a specified percentage as in an elasticity analysis, parameter levels can be adjusted based on the cost or feasibility of achieving a specified level of change and the gains in model output compared. Whereas it may be relatively simple and inexpensive to increase breeding success by $10 \%$ it would usually be impractical and/or extremely costly to increase adult survival by even $5 \%$.

\section{Conclusions}

Use of the long-term data set to incorporate breeding age specific data for survival, breeding success and skipping rates was advantageous only for approximating population structure. Little difference was observed in the magnitude or rankings of the parameter uncertainty or elasticity coefficients. 
The parameter uncertainty analysis identified probability of staying and breeder survival as the parameters that would result in the greatest improvements in model precision if tighter estimates could be achieved. The elasticity analysis based on $\pm 5 \%$ of mean mortality identified probability of first breeding as having the greatest potential to increase (or decrease) population growth rate. Whereas, the elasticity analysis based on $\pm 5 \%$ of mean survival identified breeder survival, probability of first breeding, probability of staying, re-appearance rate of prebreeders $>3$ years and non-breeder survival as all having a large influence on population growth rate. There is a lack of good empirical data for emigration and pre-breeder survival rates. Estimates of the probability of first breeding at age $x$, which are necessary for building a robust age- or stage-structured model, are also lacking for procellariiformes.

Future research will need to explore the variability in parameter estimates among populations and the potential existence and forms of density dependence and compensatory versus additive mortality if models exploring the impacts of harvest are to be useful.

The advantages of using a multiple regression equation to summarize the model include distillation of the model into a single equation, the ability to predict model outcomes as well as the elasticity in one step, the ability to explore the effects of interactions in addition to individual parameters and greater speed of computation.

It is important to include both individual parameters and interactions in perturbation analyses. Despite the high proportion of weak interactions in the parameter uncertainty and elasticity analyses, choosing to ignore them without first checking their influence can lead to misleading interpretation of individual parameters.

The choice of whether to alter survival or mortality rates can have a large impact on outcomes of the elasticity analysis. Adjusting survival rather than mortality rates will always increase the importance of survival parameters because altering proportions closer to one by a specified percentage results in a wider parameter range.

The interpretation of elasticity and parameter uncertainty analyses differ. Parameter uncertainty analysis ranks the importance of parameters based on their potential to influence population growth rate when changed from their lower to their upper value with all other parameters held at their mean values. Parameter uncertainty analysis is important for setting research priorities because it identifies parameters where reducing variance in parameter estimation (reduction in its estimated range) can lead to the greatest increase in precision of predicted population growth rates. Elasticity analysis ranks the importance of parameters based on their potential to influence population growth rate when changed by a set percentage from the mean. Elasticity analysis identifies where management actions that manipulate demographic parameter levels can be most effective in altering population growth rates.

Both elasticity and parameter uncertainty analyses only identify the potential for change in population growth rate. Whether that potential can be realized requires consideration of the biological and logistical constraints on achieving changes in parameter levels or improving parameter estimates. The choice of elasticity or parameter uncertainty analysis and methods of parameterization should depend on the specific objectives of a modelling exercise.

\section{Acknowledgements}

We are very grateful to Stuart Bradley and Ron Wooller for allowing one to use data from the Fisher Island Short-tailed Shearwater study. We would also like to thank Murray Efford and two anonymous reviewers for their comments on this manuscript. This research was funded by a Foundation for Research Science and Technology grant to Rakiura Maori. Christine Hunter was supported by a University of Otago specified research scholarship. 
Appendix A. Multiple regression equation coefficient estimates relating individual parameter, two-way interactions and quadratic terms to population growth rate for results of the $\mathbf{5 0 0 0}$ model simulations for the parameter uncertainty analysis. * Represents regression terms significant at the 0.05 level.

\begin{tabular}{lll}
\hline Regression term & \multicolumn{2}{l}{ Estimate } \\
\cline { 2 - 3 } & Average & Breeding \\
Breeder & Age Model \\
Model & \\
\hline
\end{tabular}

\begin{tabular}{lll}
\hline Intercept & 0.415 & -0.024 \\
$\begin{array}{l}\text { Breeding success } \\
\text { (BS) }\end{array}$ & $-0.305^{*}$ & 0.002
\end{tabular}
(BS)

\begin{tabular}{|c|c|c|}
\hline $\begin{array}{l}\text { Probability of } \\
\text { breeders skip- } \\
\text { ping (BRK) }\end{array}$ & $0.196^{*}$ & 0.010 \\
\hline $\begin{array}{l}\text { Probability of non- } \\
\text { breeders skip- } \\
\text { ping (NBRK) }\end{array}$ & -0.139 & $0.040 *$ \\
\hline $\begin{array}{l}\text { Breeder survival } \\
\text { (BRS) }\end{array}$ & $1.241 *$ & $0.637 *$ \\
\hline $\begin{array}{l}\text { Non-breeder sur- } \\
\text { vival (NBS) }\end{array}$ & -0.153 & -0.048 \\
\hline $\begin{array}{l}\text { Juvenile re-appear- } \\
\text { ance rate }(\mathrm{JR})\end{array}$ & $-0.221 *$ & $-0.015^{*}$ \\
\hline $\begin{array}{l}\text { Pre-breeder re-ap- } \\
\text { pearance rate } \\
\text { for year } 1-2 \\
\left(\mathrm{PBR}_{1}\right)\end{array}$ & $-0.127^{*}$ & -0.061 \\
\hline
\end{tabular}
Pre-breeder re-ap- $\quad-0.419 \quad 0.064 *$ pearance rate for year 2-3 $\left(\mathrm{PBR}_{2}\right)$

Annual re-appearance rate for pre-breeders $>3$ years $\left(\mathrm{PBR}_{3}\right)$

Probability of Staying (PST)

Probability of first $-0.020^{*} \quad 0.035^{*}$ breeding multiplier (PFB)

\begin{tabular}{|c|c|c|}
\hline Immigration & $-0.062 *$ & $-0.020 *$ \\
\hline $\mathrm{BS} \times \mathrm{BRK}$ & $-0.158 *$ & $-0.005^{*}$ \\
\hline $\mathrm{BS} \times \mathrm{NBRK}$ & 0.063 & $-0.005^{*}$ \\
\hline $\mathrm{BS} \times \mathrm{BRS}$ & $-0.214^{*}$ & $-0.033^{*}$ \\
\hline $\mathrm{BS} \times \mathrm{JR}$ & $0.106^{*}$ & $0.019 *$ \\
\hline $\mathrm{BS} \times \mathrm{PBR}_{1}$ & $0.084^{*}$ & $0.011^{*}$ \\
\hline $\mathrm{BS} \times \mathrm{PBR}_{2}$ & $0.087^{*}$ & 0.007 \\
\hline $\mathrm{BS} \times \mathrm{PBR}_{3}$ & $0.314^{*}$ & $0.037 *$ \\
\hline $\mathrm{BS} \times \mathrm{NBRS}$ & $-0.266^{*}$ & -0.007 \\
\hline $\mathrm{BS} \times \mathrm{PST}$ & $0.467^{*}$ & $0.077^{*}$ \\
\hline $\mathrm{BS} \times \mathrm{PFB}$ & $0.045^{*}$ & $0.009 *$ \\
\hline $\mathrm{BS} \times \mathrm{IMM}$ & $0.033^{*}$ & $0.005^{*}$ \\
\hline $\mathrm{BRK} \times \mathrm{NBRK}$ & -0.028 & -0.002 \\
\hline $\mathrm{BRK} \times \mathrm{BRS}$ & $-0.491 *$ & $-0.086^{*}$ \\
\hline $\mathrm{BRK} \times \mathrm{JR}$ & $-0.041 *$ & $-0.006^{*}$ \\
\hline $\mathrm{BRK} \times \mathrm{PBR}_{1}$ & $-0.037 *$ & $-0.007^{*}$ \\
\hline $\mathrm{BRK} \times \mathrm{PBR}_{2}$ & 0.000 & 0.001 \\
\hline $\mathrm{BRK} \times \mathrm{PBR}_{3}$ & -0.082 & $-0.027 *$ \\
\hline $\mathrm{BRK} \times \mathrm{NBRS}$ & $0.536^{*}$ & $0.136^{*}$ \\
\hline $\mathrm{BRK} \times \mathrm{PST}$ & $-0.122 *$ & $-0.031 *$ \\
\hline $\mathrm{BRK} \times \mathrm{PFB}$ & $-0.009 *$ & $-0.004^{*}$ \\
\hline BRK × IMM & -0.006 & -0.001 \\
\hline $\mathrm{NBRK} \times \mathrm{BRS}$ & $-0.139 *$ & $-0.038 *$ \\
\hline NBRK $\times$ JR & -0.014 & $-0.006^{*}$ \\
\hline $\mathrm{NBRK} \times \mathrm{PBR}_{1}$ & 0.003 & -0.003 \\
\hline $\mathrm{NBRK} \times \mathrm{PBR}_{2}$ & -0.002 & -0.004 \\
\hline $\mathrm{NBRK} \times \mathrm{PBR}_{3}$ & 0.076 & -0.007 \\
\hline $\mathrm{NBRK} \times \mathrm{NBRS}$ & $0.246^{*}$ & $0.045^{*}$ \\
\hline NBRK × PST & $-0.049 *$ & $-0.013^{*}$ \\
\hline NBRK $\times$ PFB & $-0.004^{*}$ & $-0.001 *$ \\
\hline NBRK $\times$ IMM & -0.002 & $-0.002 *$ \\
\hline $\mathrm{BRS} \times \mathrm{JR}$ & $-0.157^{*}$ & $-0.037 *$ \\
\hline $\mathrm{BRS} \times \mathrm{PBR}_{1}$ & $-0.075^{*}$ & $-0.032 *$ \\
\hline $\mathrm{BRS} \times \mathrm{PBR}_{2}$ & -0.064 & $-0.036^{*}$ \\
\hline $\mathrm{BRS} \times \mathrm{PBR}_{3}$ & $-0.509 *$ & $-0.063 *$ \\
\hline $\mathrm{BRS} \times \mathrm{NBRS}$ & $0.330^{*}$ & $0.042 *$ \\
\hline $\mathrm{BRS} \times \mathrm{PST}$ & $-0.575^{*}$ & $-0.105^{*}$ \\
\hline $\mathrm{BRS} \times \mathrm{PFB}$ & $-0.038 *$ & $0.009 *$ \\
\hline $\mathrm{BRS} \times \mathrm{IMM}$ & $-0.045^{*}$ & $-0.014^{*}$ \\
\hline $\mathrm{JR} \times \mathrm{PBR}_{1}$ & $0.028 *$ & $0.020 *$ \\
\hline $\mathrm{JR} \times \mathrm{PBR}_{2}$ & $0.045^{*}$ & $0.020^{*}$ \\
\hline $\mathrm{JR} \times \mathrm{PBR}_{3}$ & $0.186^{*}$ & $0.099 *$ \\
\hline $\mathrm{JR} \times \mathrm{NBRS}$ & $-0.085^{*}$ & $-0.014^{*}$ \\
\hline $\mathrm{JR} \times \mathrm{PST}$ & $0.245^{*}$ & $0.133^{*}$ \\
\hline $\mathrm{JR} \times \mathrm{PFB}$ & $0.024^{*}$ & $0.015^{*}$ \\
\hline $\mathrm{JR} \times \mathrm{IMM}$ & $0.014^{*}$ & $0.007 *$ \\
\hline $\mathrm{PBR}_{1} \times \mathrm{PBR}_{2}$ & $0.031 *$ & 0.011 \\
\hline $\mathrm{PBR}_{1} \times \mathrm{PBR}_{3}$ & $0.142 *$ & $0.065^{*}$ \\
\hline
\end{tabular}




\begin{tabular}{|c|c|c|}
\hline $\mathrm{PBR}_{1} \times \mathrm{NBRS}$ & -0.028 & -0.013 \\
\hline $\mathrm{PBR}_{1} \times \mathrm{PST}$ & $0.167 *$ & $0.090^{*}$ \\
\hline $\mathrm{PBR}_{1} \times \mathrm{PFB}$ & $0.016^{*}$ & $0.010^{*}$ \\
\hline $\mathrm{PBR}_{1} \times \mathrm{IMM}$ & $0.010^{*}$ & $0.005^{*}$ \\
\hline $\mathrm{PBR}_{2} \times \mathrm{PBR}_{3}$ & $0.118^{*}$ & $0.066^{*}$ \\
\hline $\mathrm{PBR}_{2} \times \mathrm{NBRS}$ & -0.060 & 0.024 \\
\hline $\mathrm{PBR}_{2} \times \mathrm{PST}$ & $0.155^{*}$ & $0.086^{*}$ \\
\hline $\mathrm{PBR}_{2} \times \mathrm{PFB}$ & $0.013^{*}$ & $0.009 *$ \\
\hline $\mathrm{PBR}_{2} \times \mathrm{IMM}$ & $0.013 *$ & $0.004^{*}$ \\
\hline $\mathrm{PBR}_{3} \times \mathrm{NBRS}$ & -0.081 & $-0.063^{*}$ \\
\hline $\mathrm{PBR}_{3} \times \mathrm{PST}$ & $0.675^{*}$ & $0.268^{*}$ \\
\hline $\mathrm{PBR}_{3} \times \mathrm{PFB}$ & $0.031 *$ & $-0.012^{*}$ \\
\hline $\mathrm{PBR}_{3} \times \mathrm{IMM}$ & $0.055^{*}$ & $0.029 *$ \\
\hline $\mathrm{NBRS} \times \mathrm{PST}$ & $-0.297 *$ & $-0.033 *$ \\
\hline $\mathrm{NBRS} \times \mathrm{PFB}$ & $-0.017 *$ & $0.008 *$ \\
\hline $\mathrm{NBRS} \times \mathrm{IMM}$ & $-0.019 *$ & $-0.005^{*}$ \\
\hline $\mathrm{PST} \times \mathrm{PFB}$ & $0.040 *$ & $-0.014^{*}$ \\
\hline $\mathrm{PST} \times \mathrm{IMM}$ & $0.061 *$ & $0.034 *$ \\
\hline $\mathrm{PFB} \times \mathrm{IMM}$ & $0.006^{*}$ & $0.004^{*}$ \\
\hline $\mathrm{BS} \times \mathrm{BS}$ & -0.074 & $-0.018^{*}$ \\
\hline $\mathrm{BRK} \times \mathrm{BRK}$ & 0.040 & 0.003 \\
\hline $\mathrm{NBRK} \times \mathrm{NBRK}$ & -0.004 & $-0.006^{*}$ \\
\hline $\mathrm{BRS} \times \mathrm{BRS}$ & $0.242 *$ & $0.047 *$ \\
\hline $\mathrm{JR} \times \mathrm{JR}$ & $-0.033^{*}$ & $-0.060^{*}$ \\
\hline $\mathrm{PBR}_{1} \times \mathrm{PBR}_{1}$ & 0.009 & $-0.028 *$ \\
\hline $\mathrm{PBR}_{2} \times \mathrm{PBR}_{2}$ & -0.029 & -0.019 \\
\hline $\mathrm{PBR}_{3} \times \mathrm{PBR}_{3}$ & 0.065 & -0.039 \\
\hline $\mathrm{NBRS} \times \mathrm{NBRS}$ & 0.037 & 0.033 \\
\hline $\mathrm{PST} \times \mathrm{PST}$ & $0.243^{*}$ & $-0.062 *$ \\
\hline $\mathrm{PFB} \times \mathrm{PFB}$ & $-0.012 *$ & $-0.018 *$ \\
\hline $\mathrm{IMM} \times \mathrm{IMM}$ & $-0.001 *$ & $-0.004^{*}$ \\
\hline
\end{tabular}

\section{References}

Beck, M.B., 1983. Sensitivity analysis, calibration and validation. In: Orlob, G.T. (Ed.), Mathematical Modelling of Water Quality: Streams Lakes and Reservoirs. International Series on Applied Systems Analysis, vol. 12. Wiley, Chichester, pp. 425-467.

Bradley, J.S., Wooller, R.D., 1989. Philopatry and age of first-breeding in long-lived birds. ACTA XX Cong. Int. Orn., pp. 1657-1665.

Bradley, J.S., Wooller, R.D., Skira, I.J., Serventy, D.L., 1989. Age-dependent survival of breeding Short-tailed Shearwaters Puffinus tenuirostris. Ibis 58, 175-188.

Bradley, J.S., Skira, I.J., Wooller, R.D., 1991. A long-term study of Short-tailed Shearwaters Puffinus tenuirostris on Fisher Island, Australia. J. Anim. Ecol. 133 (Suppl.1.), 55-61.
Bradley, J.S., Gunn, B.M., Skira, I.J., Meathrel, C.E., Wooller, R.D., 1999. Age-dependent prospecting and recruitment to a breeding colony of Short-tailed Shearwaters Puffinus tenuirostris. Ibis 141, 277-285.

Brault, S., Caswell, H., 1993. Pod-specific demography of killer whales (Orcinus orca). Ecology 74, 1444-1454.

Brooke, M., 1990. The Manx Shearwater. Poyser, London.

Burgman, M.A., Ferson, S., Akcakaya, H.R., 1993. Risk Assessment in Conservation Biology. Chapman and Hall, London, p. 314.

Caswell, H., 1978. A general formula for the sensitivity of population growth rate to changes in life history parameters. Theor. Popul. Biol. 14, 215-230.

Caswell, H., 1989. Matrix Population Models: Construction, Analysis, and Interpretation. Sinauer, USA, p. 328.

Caswell, H., 2000. Prospective and retrospective analyses: their roles in conservation biology. Ecology 81, 619-627.

Caughley, G., 1977. Analysis of Vertebrate Populations. Wiley, London, p. 234.

Crook, K.R., Sanjayan, M.A., Doak, D.F., 1998. New insights on cheetah conservation through demographic modeling. Conserv. Biol. 12, 889-895.

Croxall, J.P., Rothery, P., Pickering, S.P.C., Prince, P.A., 1990. Reproductive performance, recruitment and survival of Wandering Albatross Diomedea exulans at bird island, South Georgia. J. Anim. Ecol. 59, 775-796.

de Kroon, H., Plaisier, A., van Groenendael, J., Caswell, H., 1986. Elasticity: the relative contribution of demographic parameters to population growth rate. Ecology 67, 14271431.

Dixon, P., Friday, N., Ang, P., Heppell, S.S., Kshatriya, M., 1997. In: Tuljapurkar, S., Caswell, H. (Eds.), Sensitivity Analysis of Structured-Population Models for Management and Conservation. Chapman and Hall, New York, pp. $471-514$.

Ehrlen, J., van Groenendael, J., 1998. Direct perturbation analysis for better conservation. Conserv. Biol. 12, 470474.

Goodman, D., 1980. Demographic intervention for closely managed populations. In: Soule, M.E., Wilcox, B.A. (Eds.), Conservation Biology: An Evolutionary-Ecological Perspective. Sinauer, Sunderland, MA.

Hamby, D.M., 1994. A review of techniques for parameter sensitivity analysis of environmental models. Environ. Monitor. Assess. 32, 135-154.

Hamilton, S., Moller, H., 1995. Can PVA models using computer packages offer useful conservation advice? Sooty Shearwaters Puffinus griseus in New Zealand as a case study. Biol. Consev. 73, 107-117.

Heppell, S.S., 1998. Application of life-history theory and population model analysis to turtle conservation. Copeia 2, 367-375.

Heppell, S.S., Crowder, L.B., Caswell, H., 2000. Life histories and elasticity patterns: perturbation analysis for species with minimal demographic data. Ecology 81, 654-665.

Iman, R.L., Helton, J.C., 1988. An investigation of uncertainty and sensitivity analysis techniques for computer models. Risk Anal. 8, 71-90. 
Janssen, P.H.M., 1994. Assessing sensitivities and uncertainties in models: a critical evaluation. In: Grasman, J., van Straten, G. (Eds.), Predictability and Nonlinear Modelling in Natural Sciences and Economics. Kluwer Academic, Netherlands, pp. 344-361.

Kleijnen, J.P.C., 1994. Sensitivity analysis versus uncertainty analysis: when to use what? In: Grasman, J., van Straten, G. (Eds.), Predictability and Nonlinear Modelling in Natural Sciences and Economics. Kluwer Academic, Netherlands, pp. 322-333.

Lebreton, J., Burnham, K.P., Clobert, J., Anderson, D.R., 1992. Modeling survival and testing biological hypotheses using marked animals: a unified approach with case studies. Ecol. Monographs 62, 67-118.

Leslie, P.H., 1945. On the use of matrices in certain population mathematics. Biometrika 33, 183-212.

Mainland, D., Herrera, L., Sutcliffe, M.I., 1956. Statistical Tables for Use with Binomial Samples - Contingency Tests, Confidence Limits, and Sample Size Estimates. Department Of Medical Statistics, New York University College Of Medicine, New York, p. 83.

Marchant, S., Higgins, P.J. (Eds.), 1990. Handbook of Australian, New Zealand and Antarctic Birds: Vol. 1 Part A, Ratites to Petrels. Oxford University Press, Melbourne.

McCarthy, M.A., Burgman, M.A., Ferson, S., 1995. Sensitivity analysis for models of population viability. Biol. Conserv. 73, 93-100.

McCarthy, M.A., Burgman, M.A., Ferson, S., 1996. Logistic sensitivity and bounds for extinction risks. Ecol. Model. 86, 297-303.

Moller, H., 1996. Customary use of indigenous wildlife towards a bicultural approach to conserving New Zealand's biodiversity. In: McFagen, B., Simpson, P. (Eds.), Biodiversity: Papers from a Seminar Series on Biodiversity. Dept. of Conservation, Wellington, pp. 89-125.

Norman, F.I., 1985. Localised declines in colonies of the Short-tailed Shearwater: an explanation. Papers Proc. R. Soc. Tasmania 119, 103-107.

Pickering, S.P.C., 1989. Attendance patterns and behavior in relation to experience and pair-bond formation in the Wandering Albatross Diomedea exulans at South Georgia. Ibis $131,183-195$.

Possingham, H.P., Lindermayer, D.B., Norton, T., 1993. A framework for the improved management of threatened species based on population viability analysis. Pacific Conserv. Biol. 1, 39-45.

Russell, R.W., 1999. Comparative demography and life history tactics of seabirds: implications for conservation and marine monitoring. Am. Fish. Soc. Symp. 23, 51-76.

Serventy, D.L., 1967. Aspects of the population ecology of the Short-tailed Shearwater Puffinus tenuirostris. Proc. 14th Int. Orn. Congr., pp. 165-190.

Serventy, D.L., Curry, P.J., 1984. Observations on colony size, breeding success, recruitment and inter-colony dispersal in a Tasmanian colony of Short-tailed Shearwaters Puffinus tenuirostris over a 30-year period. Emu 84, 71-79.
Skira, I.J., 1990. Human exploitation of the Short-tailed Shearwater (Puffinus tenuirostris). Proc. R. Soc. Tasmania 124, 77-90.

Skira, I.J., Wapstra, J.E., Towney, G.N., Naarding, J.A., 1986. Conservation of the Short-tailed Shearwater Puffinus tenuirostris in Tasmania, Australia. Biol. Conserv. 37, 225236.

Slooten, E., Fletcher, D., Taylor, B. (in press). Taking account of uncertainty in management: is Hector's dolphin at risk due to mortality in gillnet fisheries? Conserv. Biol.

Starfield, A.M., 1997. A pragmatic approach to modelling for wildlife management. J. Wildl. Manage. 61, 261-270.

Starfield, A.M., Bleloch, A.L., 1986. Building Models for Conservation and Wildlife Management. Macmillan, New York, p. 253.

Swartzman, G.L., 1979. A comparison of plankton simulation models emphasizing their applicability to impact assessment. J Environ. Manage. 9, 145-163.

Swartzman, G.L., Kaluzny, S.P., 1987. Ecological Simulation Primer. Macmillan, New York, p. 370.

Taiepa, T., Lyver, P., Horsley, P., Davis, J., Bragg, M., Moller, H., 1997. Co-management of New Zealand's conservation estate by Maori and pakeha: a review. Environ. Conserv. 24, 236-250.

Tomovic, R., 1963. Sensitivity Analysis of Dynamic Systems. McGraw-Hill, New York.

van Groenendael, J.H., de Kroon, H., Caswell, H., 1988. Projection matrices in population biology. TREE 3, 264269.

Weimerskirch, H., Jouventin, P., 1987. Population dynamics of the Wandering albatross, Diomedea exulans, of the Crozet islands: causes and consequences of the population decline. Oikos 49, 315-322.

Weimerskirch, H., Brothers, N., Jouventin, P., 1996. Population dynamics of Wandering albatross Diomedia exulans and Amsterdam albatross D. amsterdamensis in the Indian Ocean and their relationships with long-line fisheries: conservation implications. Biol. Conserv. 79, 257-270.

Wooller, R.D., Bradley, J.S., 1999. Causes and consequences of some reproductive choices by Short-tailed Shearwaters Puffinus tenuirostris. In: Adams, N.J., Slowtow, R.H. (Eds.) Proc. 22 Int. Ornithol. Congr. Birdlife, South Africa, Johannesburg, pp. 1155-1161.

Wooller, R.D., Bradley, J.S., Skira, I.J., Serventy, D.L., 1988. Factors contributing to reproductive success in Short-tailed Shearwaters (Puffinus tenuirostris). Acta Xix Congr. Int. Orn. 1, 848-856.

Wooller, R.D., Bradley, J.S., Skira, I.J., Serventy, D.L., 1989. Short-tailed Shearwater. In: Newton, I. (Ed.), In Lifetime Reproduction in Birds. Academic Press, London, pp. 405417.

Wooller, R.D., Bradley, J.S., Skira, I.J., Serventy, D.L., 1990. Reproductive success of Short-tailed Shearwaters Puffinus tenuirostris in relation to their age and breeding experience. J. Anim. Ecol. 59, 161-170. 